\title{
CEREBRAL SCIENCE
}

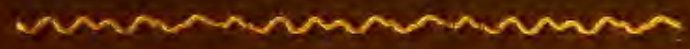
WALLACE WOOD 
19.20 .194$.

Mallau Nood 


\section{CEREBRAL SCIENCE}

STUDIES IN ANATOMICAL PSYCHOLOGY

ZA Jbook for Zintists, \physicians, allo Teacbers

BY

W A L LACE WOOD, M. D.

PROFESSOR OF HISTORY OF ART IN THE NEW YORK UNIVERSITY

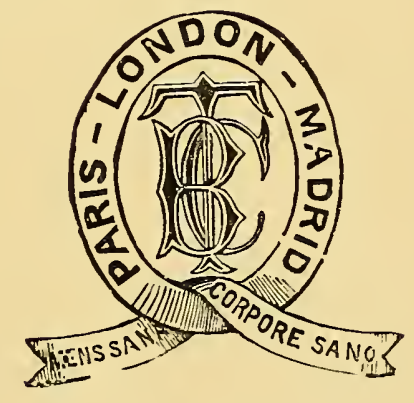

LONDON

B A I L L I ÉRE, T I D A L A N D COX

8, HENRIETTA STREET, STRAND

I 90 I

[All rights reserzed] 
Build thee more stately mansions, O my soul! As the swift seasons roll;

Leave thy low-vaulted past,

Let each new temple, nobler than the last, Shut thee from heaven with a dome more vast, Till thou at length art free, Leaving thine outgrown shell by life's unresting sea. 'The Chambered Nautilus,' O. W. Holmes. 
TO THE MEMORY

OF

MY FIRST TWO MASTERS IN PSYCHOLOGY, TAINE AND BROCA 
Digitized by the Internet Archive in 2010 with funding from

Open Knowledge Commons and Harvard Medical School 


\section{P R E F A C E}

THE considerable advance in the science of man during the past century has been due to the method. of comparative anatomy, the comparing together of all living creatures. To know one animal organism alone, even man, is to know nothing. We only know by comparison.

Psychology to-day needs the same method-comparison. The mind and character of man should be compared with that of the lion, the bull, and the lamb-all the creatures below him, as well as with the highest ideals of art and religion above him.

Animals influence both history and biography. Every nation has its emblem. It might be maintained that the character of the lion, the eagle, and the wolf have the closest bearing upon the formation of the temper of a nation destined to military supremacy, while the animus of the lamb, the ox, and the horse are not less important in view of the industrial disposition. Without going so far as this, it is perfectly certain that we must study the brains of animals if we are to arrive at a knowledge of the composition of human nature.

Character of brutes, character of men, character of ' gods,' such is our theme. 
'Characterology' must first make a scheme of the brains of each animal type, a comparative psychology of animals and men.

It must then make a study of the brains of eminent men, historical examples, make a true comparative biography, a characterology of heroes.

It must also study the characters in mythology, fiction, sculpture, and painting, making a third characterology - that of ideals.

How to form the individual character, characterology; how to form the national character, ethology-here is the practical aim.

Do we find it a novel idea to go to the brains of animals for object-lessons? Again, it might be maintained that every animal that lives has something to give us. We can get power from the horse, attachment from the sheep, firmness and stability from the ox, persistence from the wolf, fidelity from the dog, felicity from the cat, industry from the beaver, success from the elephant, and the art of conquest from the lion.

What now is their claim to utility? If we discover the panicles and lobules of these qualities in the animal spheres and in the human as well, and identify the two, the study of character becomes an exact science; psychology begins a new epoch by comparison of brains. The question of ethics, morals, and how to form the national character, begins to assume scientific shape when these lobules are traced from their deepest bed to their highest rise, sculptured in the brains of man and woman.

The book has no materialistic bias. One is not a 
believer in matter and force, but rather a believer in spirit and form. The results of cerebral study will be likely to offer a sound basis for spirituality and Christianity. The work is addressed to clergymen, to teachers, physicians, artists, writers, parents, educators, and trainers, to all interested in human nature, and the formation of character.

Out of the theoretical science of comparative psychology, founded upon comparison of the brain gyres, will grow the practical science, ethology.

Ethology, how to regenerate man, how to make the better man and the better woman, how to build the new body, the new brain, and the new city, how to shape the new world.

* $\quad * \quad$ *

Our work is a study of form. Anatomical psychology can not be less worthy than physiological psychology.

The cardinal sciences as we see them are chemistry, physics, morphics, psychics-or theory of matter, theory of force, theory of form, and theory of spirit. Chemistry and physics are fundamental sciences, morphics and psychics are supernal sciences. Form is divine; the école spiritualiste should not give over to l'école materialiste the eidos and the morphe. In the Elysian fields, moreover, Bossuet and Goethe have joined hands. Religion and Science are reconciled.

The soul of man may be regarded as form and spirit, and as form (eidos, morphe) not less than 
spirit. The study of the form is cerebro-statics, as the study of the spirit is cerebro-dynamics.

In the head of the lion, ox, or man one finds that 'wondrous coil' the brain; the brain is the envelope of the soul. The psyche works in that coil like the snail in its shell, or as the chambered nautilus; and we may learn something of the form of the snail from its shell, its coiled envelope.

The shell does not secrete the snail, but the snail does secrete the shell. The brain does not secrete mind, but the mind does mould the brain; therefore in this exquisitely-modelled form we read the mind.

米粆

The new body, the new brain, the new city. Life creates the new body, mind creates the new brain, spirit creates the new city. Life, mind, and spirit are three grades of divine force. As anatomy and physiology go together on the first plane, so cerebrology, or cerebreology, and psychology should go together on the second, as history of literature and history of art go on the third. Thus gradually we shall renovate the corporeal sphere, the cerebral sphere, and the civic sphere.

From an historical point of view one may divide the sciences by a long line into the dark and the clear. Astrology is the dark science, astronomy is the clear. Alchemy is the dark science, chemistry 
is the clear. So phrenology is the dark science, while cerebrology and cephalometry are the clear sciences. Palmistry also is a dark science, yet, no doubt, there may be a clear science of the hand. Physiognomy is a dark science-it works by signs and intuitions; prosoponology, or the collection and classification of masks would be the clear science.

We may go somewhat further upon this line: spiritism is the dark science, psychology is the clear science; theosophy is the dark science, philosophy is the clear science. It is hard to be good, it is easy to follow Neith and Isis and yield to witchery, and to be darkly wise, but to be clear-eyed like Athena, and to arrive at good form is hard indeed; yet it is this striving, this excellence which separates Europe and the young America from the surrounding world. Slowly, very slowly, we force our way up to the classical, the standard, and the exemplary. 'Excellence doth dwell on high rocks inaccessible'; yet the humblest may work in her direction and upon her lines.

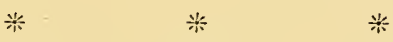

'Shädel Hirn und Seele,' the house of the soul, the mantle of the soul, and the soul; theory of the head, or cephalometry; theory of the brain, or cerebrology; theory of the psyche, psychology. Uniess one is mistaken cerebrology, or cerebral science, a study of the brain as the connecting link between the head and the soul, a connecting link between the body and the city, and again between 
mind study and character study, has an immense future.

The world is before us, the world of extension; the world is within us, the world of concentration. Both are ours, let us till the fields.

Happy are the students. The hautes études for the new century are astronomy, botany, aerostation, and cerebrology - there is enough to do. 'Laboremus.'

February 28, 1901. 


\section{B I B L I O G R A P H Y}

CEREBRO-STATICS AND CEREBRO-DYNAMICS

THE following works on the brain are reconimended to the student. Only the most necessary are here set down :

The great atlas of Retzius.

The work of Dejérine.

The new work of Professor Soury ( $\mathrm{I}, 860$ pages).

The work of Flatau and Jacobson.

The atlas and text of Brissaud.

The work of Andrew Parker.

The various works of Professor Burt Wilder.

The works of Charles Mills.

The works of Dr. Dana.

Poirier's Anatomy.

Testut's Anatomy.

Quain's Anatomy.

Eberstaller's 'Stirnhirn.'

The works of Broca.

The works of Luys.

Ferrier's 'Functions of the Brain.'

The works of Flechsig.

Gustav Mann in Jour. of Anat. and Physiol. 
Sir William Turner in Jour. of Anat. and Physiol.

Meynert in Striker's Histology.

Meynert in Avchiv. fïr Psychiatrie, vol. vii.

The works of Krueg.

The atlas of Leuret and Gratiolet.

The large atlas of Gratiolet.

The works of Cunningham.

The atlas of Fraser.

Langley on the dog in Jour. of Physiol.

The works of Gervais.

For more extended bibliography see Quain, Krueg, and Turner.

The twelve best works for psychology are the following :

I. Bossuet, 'Connaissance de Dieu et de Soi-même.'

2. Bain's 'Mental and Moral Science.'

3. Hamilton's Metaphysics.

4. Volkmann's Psychology (fourth edition).

5. Hegel on the 'Spirit.'

*6. Aristotle, 'De Anima.'

7. Plato's 'Philebus' and 'Republic.'

8. Clouston's Mental Diseases.

*9. Diogenes Laertius.

Io. Herbert Spencer's Psychology.

I I. Kant's 'Pure Reason.'

I2. Spinosa's Ethics.

All psychologies are good. Each thinker has some peculiar excellence. The above list is subject to revision. 


\section{CON T E N T S}

I

THE CEREBRAL SPHERE

PAGE

- $\quad$ I7

II

PSYCHOLOGY OF THE LAMB

- 33

III

BRAIN OF THE OX

$-47$

IV

PSYCHOLOGY OF FELIS

$-59$

Y

THE BRAIN OF MAN -

NOTES AND REFERENCES

- I I I 

I

THE CEREBRAL SPHERE 
Know thyself.

Measure all things.

Nothing too much.

It is hard to be good.

The nobler part is better than the common whole. Keep to the happy mean.

Hellenic Aphorisms. 


\section{CEREBRAL SCIENCE}

\section{I}

THE CEREBRAL SPHERE

THE opening century ought to bring us new arts and new sciences; the art of arts, the science of sciences, is the creation of the human head, the study of the human brain. Here is the new art and the new science for the opening century.

Who would follow the summit-maxim, Know thyself, has three planes of observation. Students in the veterinary college, in the zoological gardens, in the school of anthropology and criminology, see life, mind and feeling, and read character standing upon the natural, the animal, the native plane; they come down to the bed-rock of instinct and tendency. This is the natural-history plane. On this plane one often sees men worse than they are; Machiavelli and Lombroso see men thus.

Students in medicine, law, and theology observe manners and read character and study human nature upon another plane-the physiological-psychological. The physician knows men through his patients, the lawyer through his clients, the divine through his 
penitents. The three professions see men as they are. This is the human plane. ${ }^{1}$

The historian, finally, the biographer, the poet, the painter, the sculptor, draws his characters in broad, noble outlines; he places them upon pedestals, he figures them as on a height. This is the heroic plane. The sculptor, the historian, biographer, sees men better than they are.

The concrete psychologist must serve his time upon all three of these planes. He must dwell for a while in the house of man, and for a while in the house of the god, and for a while in the haunts of the animal. Two years or more in the zoological museum, two in the medical museum, and two in the art museum; two years' contemplation of the heads of animals, two years in drawing the heads of men, two years upon the heads of gods and heroes - this is his discipline.

Having served this apprenticeship, he will thereafter hold all three of the planes constantly in mind, even as Dante could hold at once an inferno, a purgatory, and a paradise. He grasps the whole. In this way he keeps his balance. When studying the invertebrata, he will not lose taste for saints and madonnas; when dealing with the sick and the mad and the sinning, he will not forget the Cæsars and the Lincolns, and 'the angel heart of man,' and 'das Gottliche.' He will not too much exalt animals, nor will he seek to debase or dethrone the immortals. ${ }^{2}$

We work to-day upon the human plane, to-morrow upon the animal plane, the next day upon the god- 


\section{SUPERIOR.}

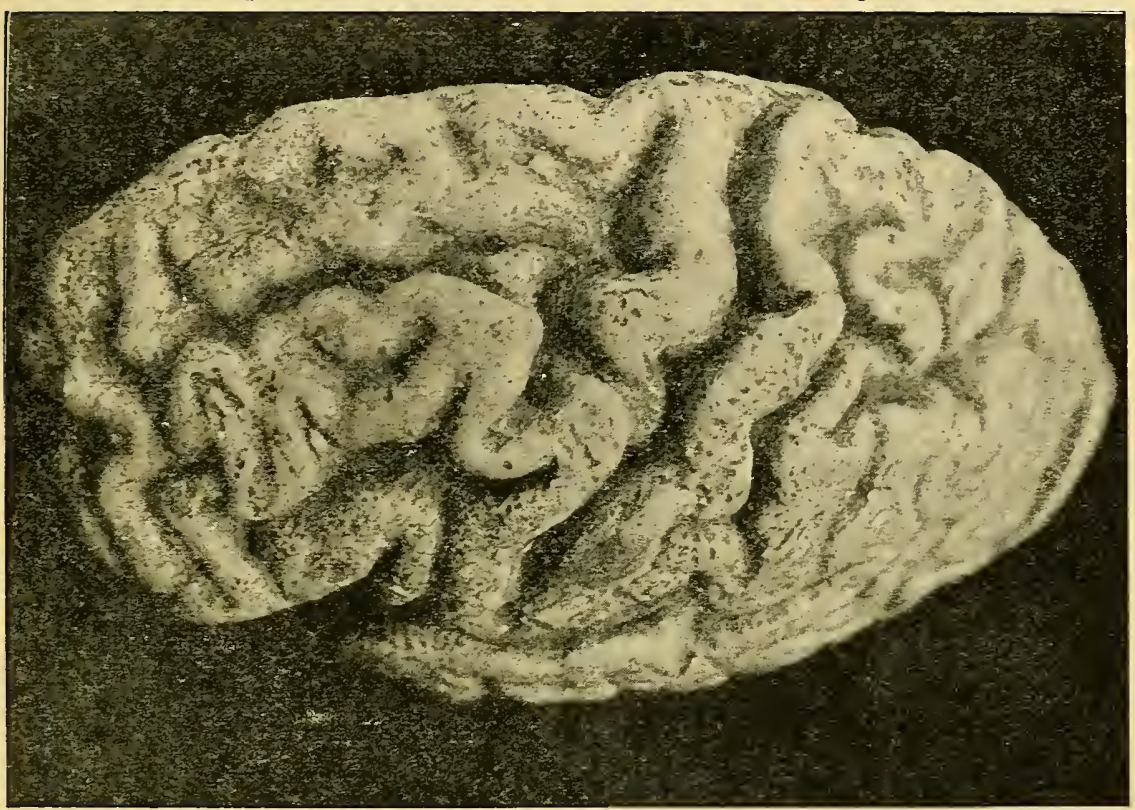

INFERIOR.

Fig. I.-The Cerebral Sphere. Brain of Man, Left Hemisphere, Vieiv near the Vertex, Profile.

The deep perpendicular fissure running downward, like a river between its two white banks, is the Rolando; this river, with its banks, is the grand motor. Anterior to this is the lobe of the great frontal dome, plainly divided into three tiers or arches: these are the first, second, and third frontal lobes or gyri. Each of these may be taken in three parts-anterior, mid, and posterior. The anterior part of the third is the salience, the junction of the second gyrus with the third; the mid portion of the third is the cap; the pars posterior is the pied, or talker, the cerebrophone. The anterior part of the second or middle lobe is not visible, but the pars medius and pars posterior are distinct; the pars posterior, active, is arrow-shaped. It is the writing centre. We see here, therefore, the creative eye and the creative pen as they appear in the soul-that is, in the cerebrum. Arching above the second stage is the superior or first frontal lobe. The anterior portion is not visible in this plate. The two parts seen are the anterior metopic and posterior metopic lobules. The motor is divisible into three parts; the superior lobule is the pes, or spirit of the foot; the middle lobule is the manus, or spirit of the arm; the inferior lobule, shaped like the lower part of a human face, is the facies, or maxilla, the spirit of the jaws-under it is seen the line of the temporal lobe. Posterior on the plate is the terminal bulb, the occipital eye. 
like. To-day the dog, to-morrow the man, the next day the god.

Shall we study body and head? Bring to the auditorium to-day bodies and heads from the zoological and ethnological museum, to-morrow bring us bodies and heads from the medical museum, and the next statues and busts from the art museum. We must see the whole.

Shall we study faces? Bring, then, to-day the faces of dogs, to-morrow faces of men, and the next the faces of the gods of Olympus. We must see the mind whole.

Is our quest harder? our glance to be more penetrating still? Is the mens our subject? To-day, then, let us work hard upon the brain of a sheep; to-morrow upon the ' cranium, ${ }^{3}$ brain, and soul' of an average man; the third day we will take those of a king, a woman, a philosopher. We must see the brain whole.

The cerebral sphere is a being, a being of form and spirit. It is opposed to the body sphere. ${ }^{4}$

Cerebral spheres are of three orders : zoomorphic, anthropomorphic, and theomorphic or heroic; or, reversing, they are superior, inferior, and lower.

Animal brains are peculiar in this: every animal is a specialist, and his brain shows it. The dog, Canis familiaris, is a professional reviler and fawner; her majesty the cat is a professional mousetamer.

The cerebral sphere of man is different from those of animals in this: that it is enormous, like a palace, or a villa, or a city; it contains every- 
thing, it is the abode of a thousand spirits rather than one. This truth is set forth in his surname, Sapiens.

The brain resembles the creature. ${ }^{5}$ The brain of a lorse looks like the horse, the brain of a cow has the serene and lowly air of the horned ruminant, a hemisphere of a black-and-tan dog resembles the dog. A swine's brain is long and coarse, it is the pith of a swine; that of the fox is sharp and fine and foxy, it is the epitome of a fox. The brain of a lamb has its forehead raised, that of a cat has its back raised. The lamb desires to love and be loved, the cat desires to rule and not be ruled.

The feline cerebrum consists chiefly of ears, claws, and haughty back ; Leo intends to place his claw upon the round world. The brain of a horse is all arching neck and pawing forefeet; that of a seal is all flippers. The cerebrum of a bear is a sack with a screw snout; that of the wild gazelle is a labyrinth of fascinating curves, a dream of gracefulness. Each has a marked style, a brand, a stamp.

The brain is the form, the language, the aim, the very spirit of the man or creature. Your brain-globe is the crystallization of your best moments. A horse is at his best when eagerly arching, pawing, prancing. A cat is most the cat when she is preparing to be incensed. It is her ears, back, and retractile griffs that have made her great; they are three of the seven wonders of the cerebral world.

Shall we seek the four others?

The four others are the mental eye of an ape, the mental foot of a man, the mental nostril of a black- 
and-tan dog, and the forehead of a horse or a lamb. But what shall we say of the talking gyrus and the anthemion?

Let us try once more. The seven wonders of the cerebral world are the mental jaws of the tiger, the mental ear of the cat, the mental eye of the ape, the anthemion of the ox, and in man the high front, the speaking lobe and the Rolando lobe.

Chief of them is the high front, the psyche, the dome of verity, beauty, humanity.

A swine is at his best when ploughing, a cow when ruminating. Her brain is the image of the ruminator, as that of the cat is a plastic mould of the able catcher and killer. A lion is at his best couchant - that is, when his haughty pride and vehement power are lying in calm repose upon his terrifically strong and very-much-ahead-of-everything pair of arms. This is as nearly as possible the description of his brain-sculpture.

A woman is at her best and happiest when she is bending over a couch, and the forebrain of a gentlewoman is essentially a heavenly bend of this fashion. So ' heaven itself might stoop to kiss.' A man is at his worst when he thrusts his under-jaw, not backward, but forward, and slowly but strongly utters the word 'mean,' dwelling on the vowel $e$, and shaking his head. A man is at his best when he says, "I will do a good work,' and draws his under-jaw, not forward, but backward. ${ }^{6}$ The brain of man images this in transcendently beautiful lines and formsforms in sculpture, and stamped, not momentarily, but permanently. It is his psychical character, his 
SUPERIOR,

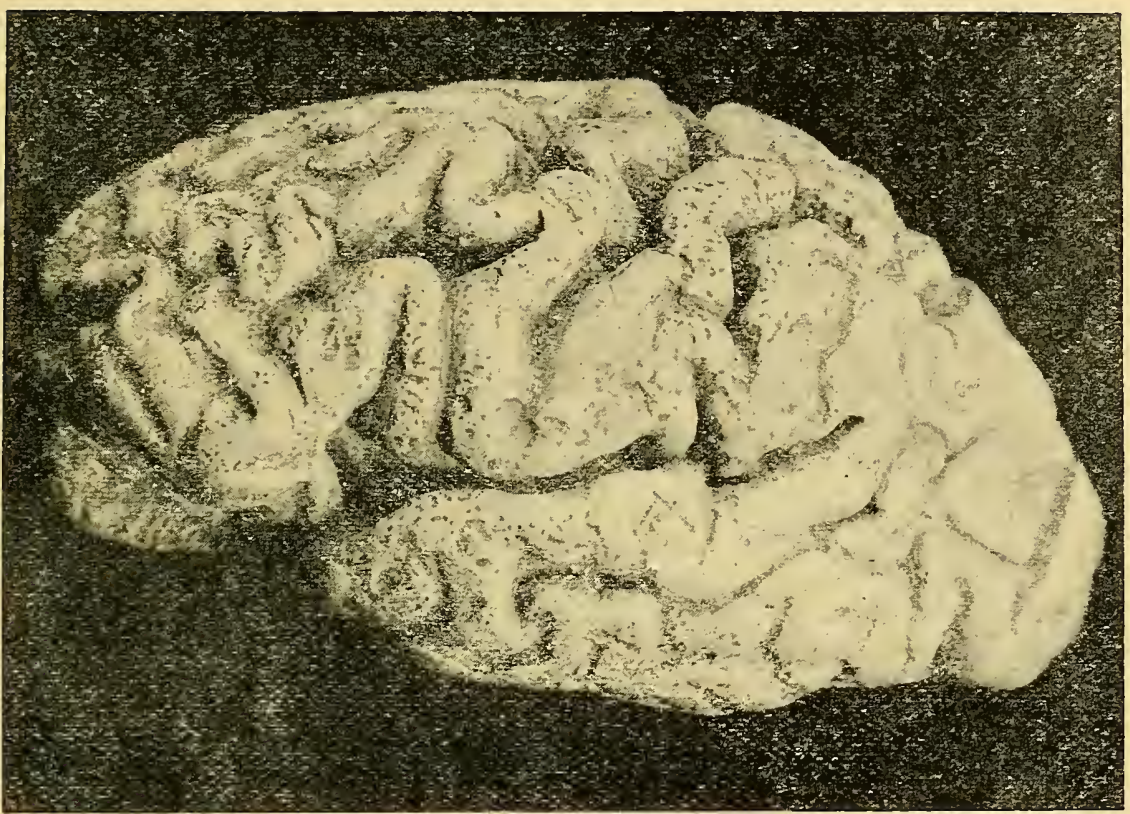

INFERIOR.

Fig. 2.-The same Hemisphere, View in Direct Profile.

The deep longitudinal fissure is the fissure of Silvius. Below it stretches the temporal lobe. The first gyrus beneath the fissure is auditory in its superior half. One observes that this half is shaped like the rim of a human ear. Inferior to this auriculate shape are displayed three lobules: anterior, the stome or sphenoidal pole; middle, the lobulus vitalis; posterior, the bulb. Posterior slightly superior is the occipital eye; posterior superior is the parietal lobule, seat of sensibility. Nearly central on the plate, on the long vertical fissure of Rolando, is the grand central lobe, the motor. Anterior to this the speech lobe with its foot-curve and the vision lobe with its footcurve are clearly delineated. 
soul's mark. This is the character of the mouths of the youths on the Parthenon frieze.

The tiger is at his. best-that is, at his worst-his royal tigerishness at its height, when he thirsts for gore, and thrusts his muzzle far forward. The tiger-brain is the sculpture of the eternal spirit of this movement.

The proper name of the tiger is the transcendently terrible mouth.* This is the name and character you read in those turgid tiger gyres when the brain membranes are removed.

The brain of an Indian panther, the most fierce of all known creatures, is full of sickles. It is a reaper whose name is death. ${ }^{7}$ That of the Indian deer is full of double curved leaps more ravishing than all the Greek scroll-work. ${ }^{8}$

The brain of an elephant is what we should expect, is exactly what it ought to be, huge, and all nose and sides. The elephant is essentially a nose at its ' greatest, finest, best,' and many in the land of the elephants bow down to Ganesa and fervently say to themselves, 'Go thou and do likewise.'

Every animal has a character, a style, an air, a genius, a talent, a peculiar virtue, spirit and essence, a soul. Open the skull and look for this; you will surely find it-find that character, genius, talent. Open the head and you will surely find the stamp. The encephalon is a plastic representation of the body at its best.

Running dogs, celeres, have strong locomotor

* The lion is the terrible arm, the tiger is the terrible mouth. This is proved by comparison of the two brains. 
gyres; the wolf lobules; fighting dogs, pugnaces, extremely ugly-looking concave, plough-shaped foreheads; the bull-dog lobules.

The black-and-tan has mental nostrils more squarecut-that is, higher developed or more excellent than those of any other creature. The universe to him is a classification of smells, an osmology.

All ' good dogs' - that is, those most accustomed to praise and head-patting-have developed upon the top of the cerebral prow a fawning-and-fidelity lobule. ${ }^{9}$ The brain prow of a wolf, per contra, is straight as a gun. He will not save your child for you; he will not guard your property for you; he will not tend your flocks for you; 'he will not go mad for joy of a morning at the sight of you; he will not die of grief when you leave him. Never; he is a Canis, a dog, but not this dog; his cour psychologique-that is to say, his brain prow-is straight as a gun-barrel, and, figuratively speaking, as hard.

This chapter doubtless requires a certain qualification. The highest, severest, most supernally beautiful of the sciences is not so simple and plain that he who runs may read. At best, perhaps, to the inexperienced eye the prepared cerebrum of Felis domestica looks like some very perfect little machine; that of the gazelle like a very perfect piece of ornamentation; that of the ox or man like nothing-a meaningless mass of intestines. We see through a glass very darkly indeed. What is required? Each art has its own materials and processes-one, paint and brush work ; another, bronze and mould work. The fortythree pairs of nerves, each of which is a pantographic 
pencil or finger, have a special art, and a material and process. One must first conceive this material and process. The material is gray matter, cerebrin -a wax of 'phosphorescent fat and nitrogenous granules,' a pate plastique made of lightning and gunpowder-and the method or mode of work very much that of the virtuoso in penmanship or the old Greek potter: it consists of flourishes, lines of beauty, interminable scrolls, meanders, curves, coils, spirals, stamens, volutes, honeysuckles, 'convolutions.' 10

This is what we note, however: the penman makes not his flourishes idly, nor are they unmeaning, but here you will find he has drawn a dragon, an eagle, a swan. So every scroll and volute on a Greek vase was a symbol or a picture.

The cerebrum is a representation of character by the mode, material and process of gyrotechnics-that is, nerve repoussé work done in a pate of 'phosphorescent fat and nitrogenous granules,' and with incredible quickness and by the running hand-that is, by flourishes.

In the study of gyrology we must first accustom ourselves to gyri style of work. Iron-work, marblework, wire-work, wood-work, penmanship, fireworks, waterworks, music also, each produces its own style of forms, features, limbs, members, designs, actions, themes, spirit or vorstellung.

Brain-work, convolution-work, also has its own.

When a child is shown an eagle drawn by an expert penman, his untrained eye cannot see the eagle for the flourishes. It is so with all eyes when 
SUPERIOR.

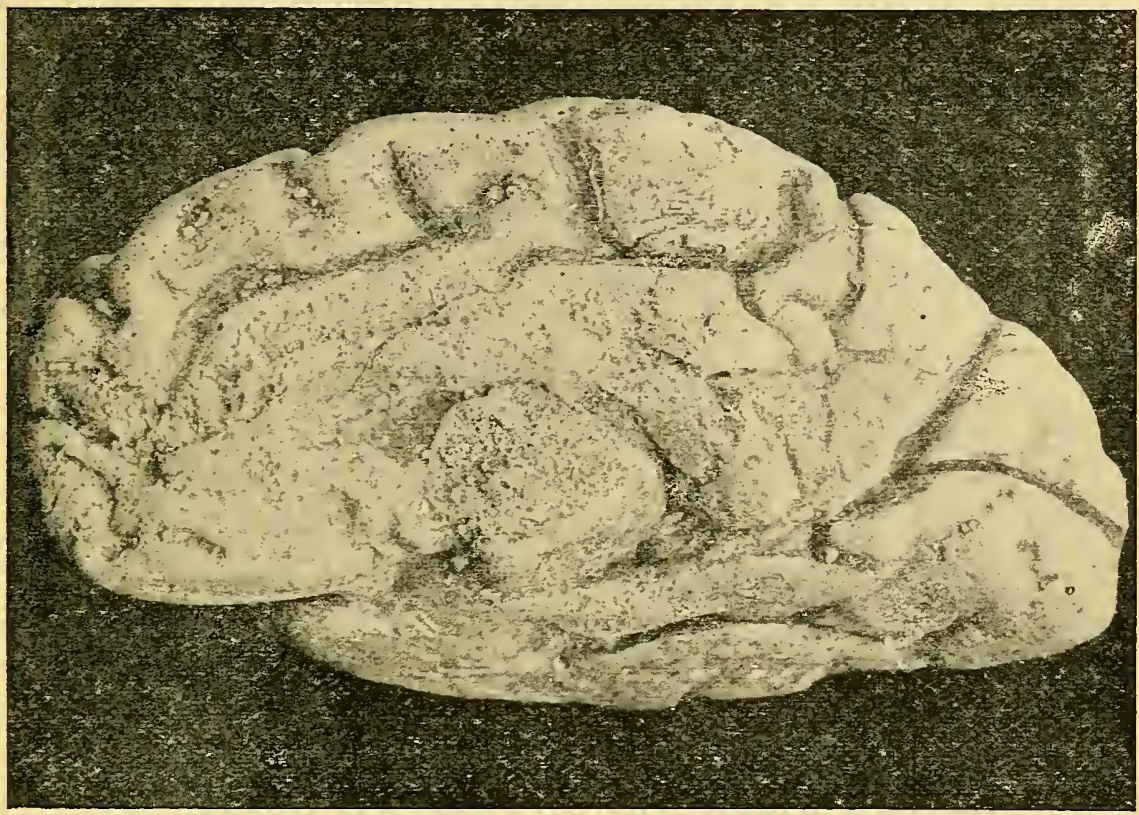

INFERIOR.

Fig. 3--The same Brain, Right Hemisphere, Inside or Mesial Surface.

Anterior is the prorean lobule. Anterior-superior are the anterior metopic and posterior metopic lobules. The form of the pair taken together is that of a lituus or knife, of which the pars anterior is the blade, and the pars posterior the handle. Superior, usually highest on the brain, oval in shape, is the hip or pes, spirit of the foot, the paracentral lobule; superior-posterior is the quadrate, centre of sensibility; posterior, triangular, is the cuneus, or bend of the eye-scroll; inferior posterior is the under-bulb or anthos, the under occipital lobe. Inferior is the sphenoido-temporal lobe, head of taste, nutrition, and vitality. At the inferior-anterior angle is the under-prorean lobule, centre of will, sagacity, attention, intention, concentration, or control.

This hemicerebrum is from a cast of a brain prepared by the Charcot process-reduced two-thirds. 
first looking at the gyri: we cannot see the organic lobules, the eidola, the psychical membra, for the convolutions.

For this reason the student should draw and model the lobules, as well as dissect them; he will then become accustomed to this peculiar style and technique. One can hardly be expected to see in the fissure of Rolando the perfect image of a hip, an arm, and a mouth.

If we assert that the brain is a copy of the body we must qualify the assertion. It is a pantographic work, a copy of the spirited action of the members of the body. In case of a high-spirited trotting horse, ${ }^{11}$ the cerebrum becomes the image of trotting. Brain lobules are formed by two laws: one the law of the organ-an eye makes an eye, an ear makes an ear; the other the law of the action, that is, the rule of the thing habitually seen and heard. I have a cast of the brain of a cabinet-maker in which the mental ey'e seems cut up into bars or boards; and another brain, that of a typographer, in which the visual area appears laid out in squares. I have one of the brain of a seamstress who died from overwork, and in her brain it appears that she has literally sawed her right arm off-not her bodily arm, but her mental arm. These specimens are curious. ${ }^{12}$

The inner is the echo of the outer. The spirit of audition thrills through us and leaves a wave of flesh upon the body, a corporeal ear, and it throws up a wave upon the cortex, which is in form auriculate. The spirit of vision grows an eye-stem without and a counter eye-stem within. ${ }^{12}$ 
Adaptations appear in the within, but they also appear in the without. The external mouth of the orator is shaped by his career as well as his internal mouth, and his internal as well as his external.

So the without appears within. The astronomer's corporeal arms hold up a telescope, and his two mental arms are sculptured both lifted up, and his mental eyes are squared and hinged in a most curious and suggestive way. The cerebrum is the $\zeta \hat{\omega} \nu$ a $\epsilon \iota \delta \omega \lambda o \nu$, the modelled image of the life that a man leads. ${ }^{13}$

The brain is a mirror of the habits of the body; and more than this, the right brain is a mirror of the forms and habits of the left side of the body, and the left brain is the mirror of the forms, habits and performances of the right side of the body. ${ }^{14}$

When the brain works under the leadership of the left hemisphere, the individual acts as an educated soul; when the brain works under the leadership of the right hemisphere, the individual acts as a naive, or native soul. The right hemisphere is often the more comely. 

II

PSYCHOLOGY OF THE LAMB 


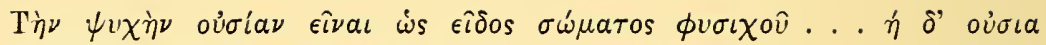
$\dot{\epsilon} \nu \tau \epsilon \lambda \epsilon \in \chi \epsilon \iota a$.

Arist. de Anim. II., I. 


\section{PSYCHOLOGY OF THE LAMB}

AMONG all the cérébrales industriales et civiles-that is, among all the brains of the industrial and civil class-we may select three as going well together.

Let us contemplate man and his two best friends, the two humble beings to whom in the course of his long and arduous struggle for a footing on the planet he owes most.

The rarn, the bull, and the heavenly twins stand first upon the zodiac-Aries, Taurus and Homo. Here is a trinity reminding us of the Golden Age.

The association marks an epoch. Before this association was formed man was rapidly degenerating toward bearishness and the wolfish and the tigerish-creeping into caves and dens, and skulking forth by night or day on a trail of blood.

It is hardly too much to say that humanity began with the Pastoral Age, the Golden Age, and that the Golden Age dawned on the day of that most fortunate association, that contrat social, between man and the members of his flock and herd. The man promises for evermore to cherish and protect, and the flock and herd promise for evermore to love, honour and obey. Peace dawns on earth and goodwill. ${ }^{15}$ 
How shall we best teach the lore of the brain gyres? The brain is like both musical art and plastic art. Let us try a musical scale.

Draw half a dozen lines across the notebook thus:

\begin{tabular}{ll}
\hline I & $\mathrm{e}$ \\
\hline II & $\mathrm{d}$ \\
\hline III & $\mathrm{c}$ \\
\hline IV & $\mathrm{b}$ \\
\hline & $\mathrm{a}$ \\
\hline
\end{tabular}

This looks like a musical clef. Let this diagram represent the brain. The five spaces will represent the five gyri of the exterior surface, the whirls or projections of the five senses.

The right hand, a, b, c, d, e, we will call posterior or sensorium-mnemonium; the left hand, I, II, III, IV, anterior or motor.

The letters a, b, c, d, e will represent the receptive vesicles of the olfactory, gustatory, auditory, optic, and spinal nerves-that is, these five spaces are sweeping coils or scrolls into which rise the scents and flavour, the music, the colours and the corporeal feelings. We may now represent the posterior, or receptorium, thus :

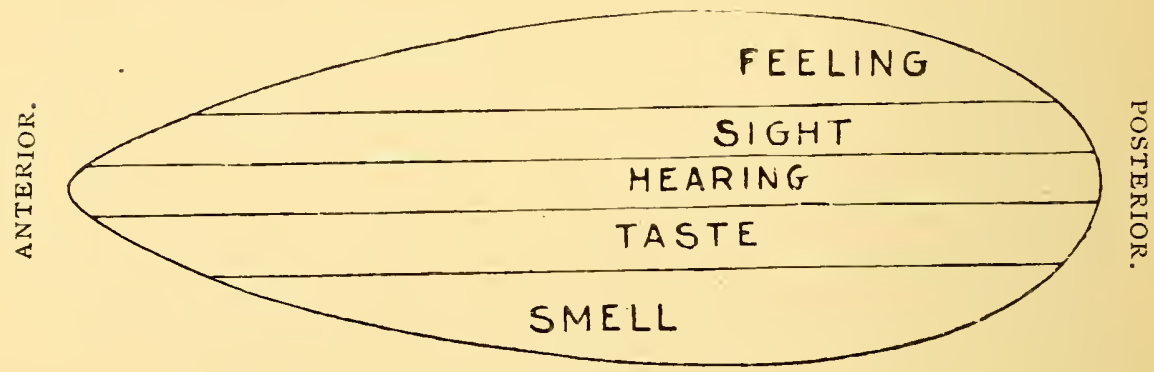


This scheme of localization will be found to answer for the brain of the sheep, the brain of the ox, and that of man. According to the English psychologists, impressions ascend through the gyri a, b, c, d, e, and descend through the gyri I, II, III, IV.

\begin{tabular}{cc}
\hline I & $\mathrm{e}$ \\
\hline II & $\mathrm{d}$ \\
\hline III $\frac{\mathrm{c}}{\mathrm{II}}$ & $\mathrm{b}$
\end{tabular}

a

Thus, smells, tastes, sounds, sights, and compound muscular and nervous feelings drive the creature to move the head and feet, the arms, jaws, and tongue.

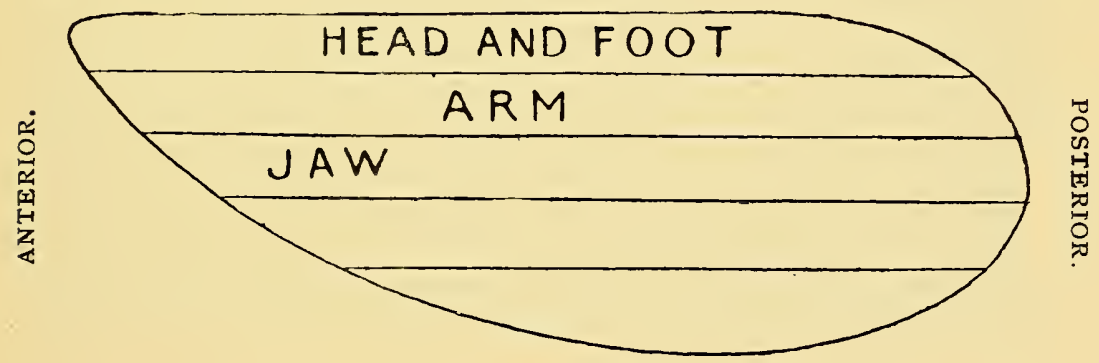

In each of the posterior gyri and each of the anterior gyri will be found a culminating whirl or centre. Thus, an olfactory centre, a gustatory centre, an auditory centre, a visual centre, and a centre of active and passive sensibility are recognised.

Or, again, we may call them lobules, and conveniently place the forefinger upon each successively, running up the scale $a, b, c, d, e$; thus, the 
olfactory lobule, the gustatory lobule, the auditory or audile lobule, the visile lobule, the tactile-motile lobule. We may call these the mental nostril, mental palate, mental ear, mental eye, and mental body.

A portion of the mental body or association centre of corporeal sensibility is hidden from view, being on the mesial or inside surface in a sixth gyrus, the arch, or gyrus fornicatus.

The six sets of impressions-olfactory, gustatory, auditory, optical, muscular and sensitive-may be grouped in three associate groups of sensations or memories. Thus, we might speak of (I) the pleasures of eating, (2) the delight of pastoral sights and sounds, and (3) the memories of experiences, both pleasant and painful; two senses to each.

On the anterior or sensory motor half we at once and easily distinguish three prominent and always more or less hinge-shaped, spiral-shaped, and armshaped lobules, which are the mental foot and mental arm and the mental facies or jaws (I, II, III).

As to the shape of these: If we examine a human arm in the flesh, we shall find prominent (I) an elbowjoint ; (2) a spiral or hollow screw of driving muscle; (3) a scroll-shape, the line of beauty; and (4) a flesh mass, the plump, handsome, or formose appearance of a well-turned limb.

These four principles of combined power-grace, ease, beauty, fulness, etc.-apply to any member, the leg, the arm, or the jaw (pes, manus, maxilla) of a human being, and also equally well to the pes, manus and maxilla of the sheep or ox; so that in the brain of each we may look for the mental foot, the mental 
arm, the mental jaw, and, remembering the four principles of the fleshly members, probe further and deeper, expecting to see the spirit of hinges and spirals and the scroll line, and the handsome mass upon any and every cerebrum.

\section{SUPERIOR .}

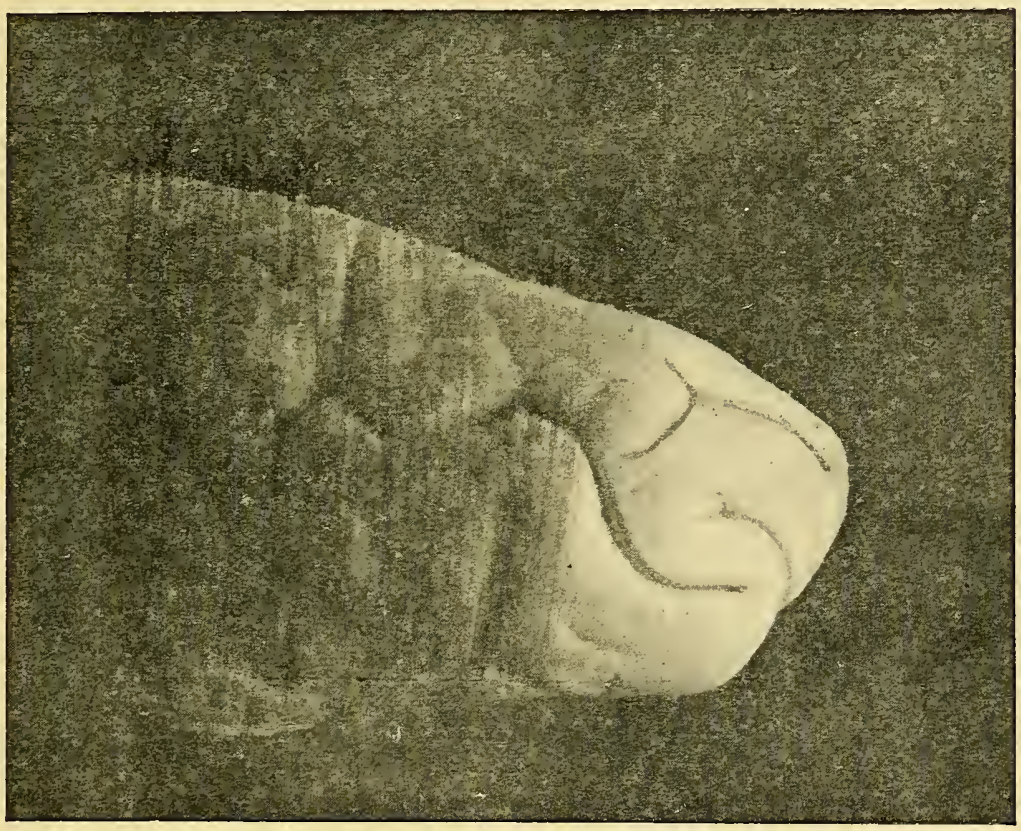

INFERIOR.

Fig. 4.-Brain of a Lamb.

Frontal lobe, or high psyche, 'head and eyes.' It consists of two or three parts: superior, the lobules of will and good-will; and inferior, the lobule of attention. The prow and eye are united by a complicated and beautiful coil.

We may be disappointed. We shall see these masses, hinges, and spirals in miniature, and we shall see them as in a glass, darkly. 
In another difficult, but equally sublime, scienceastronomy-men watch all night, happy if rewarded by one new glimpse, and this but a surmise ; but the reward for the pains taken in the pursuit of celestial

SUPERIOR.

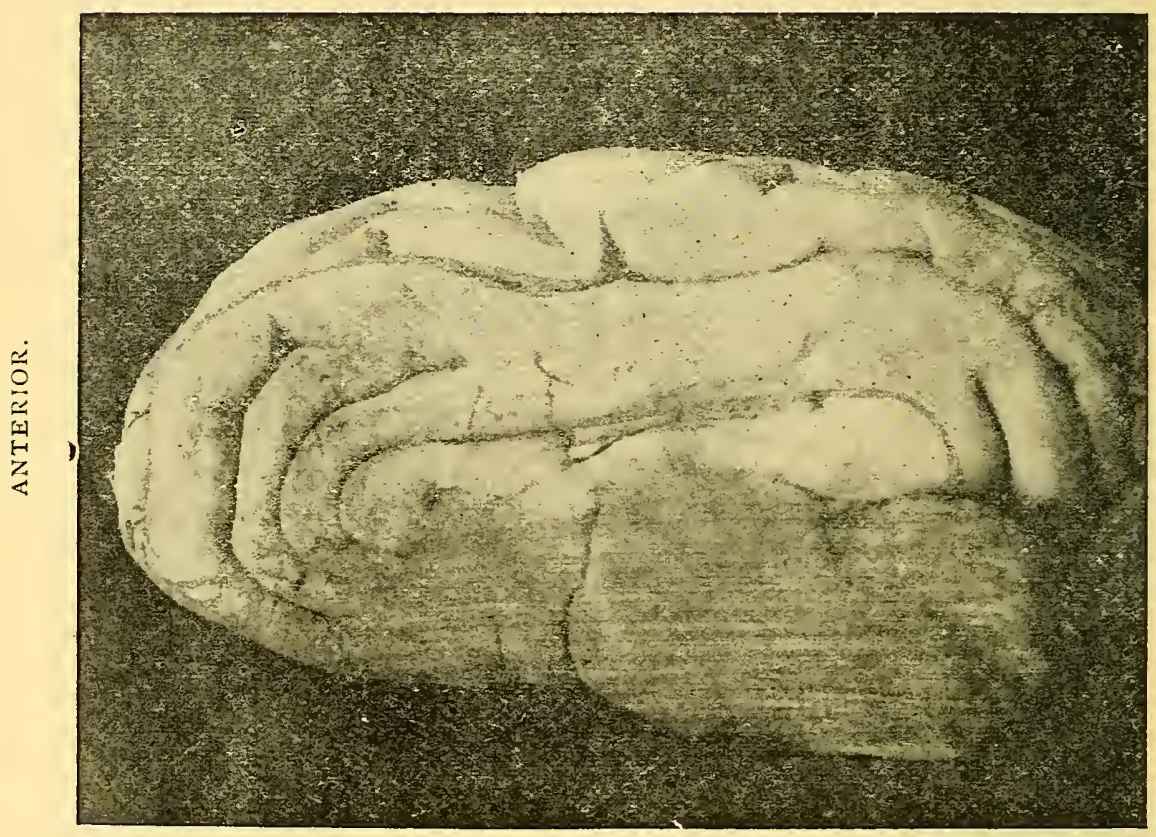

INFERICR.

Fig. 5.-Brain of a Lamb (Ovis aries).

Right hemisphere, inside or mesial surface. Anterior-superior is the kopf or head lobe; posterior-superior is the rumpf or body lobe, the posterior head; between the two, superior, is the pes or hip lobe. The superior gyrus is the gyrus marginalis; the broad gyrus, inferior to it, is the gyrus fornicatus-it rises to a head in the direction anterior-superior.

matters is in proportion to the difficulty; so is it also in spiritual--that is to say, cerebral-matters. Yet at first glance, and to the popular eye, both brains and skies are disappointing. 
Our great father Wordsworth has shown us how men who 'pry and pore' do not look as happy as do those who dance to the tune of the organ-grinder.

It is a curious fact that in the cerebral body not

SUPEIIIOR.

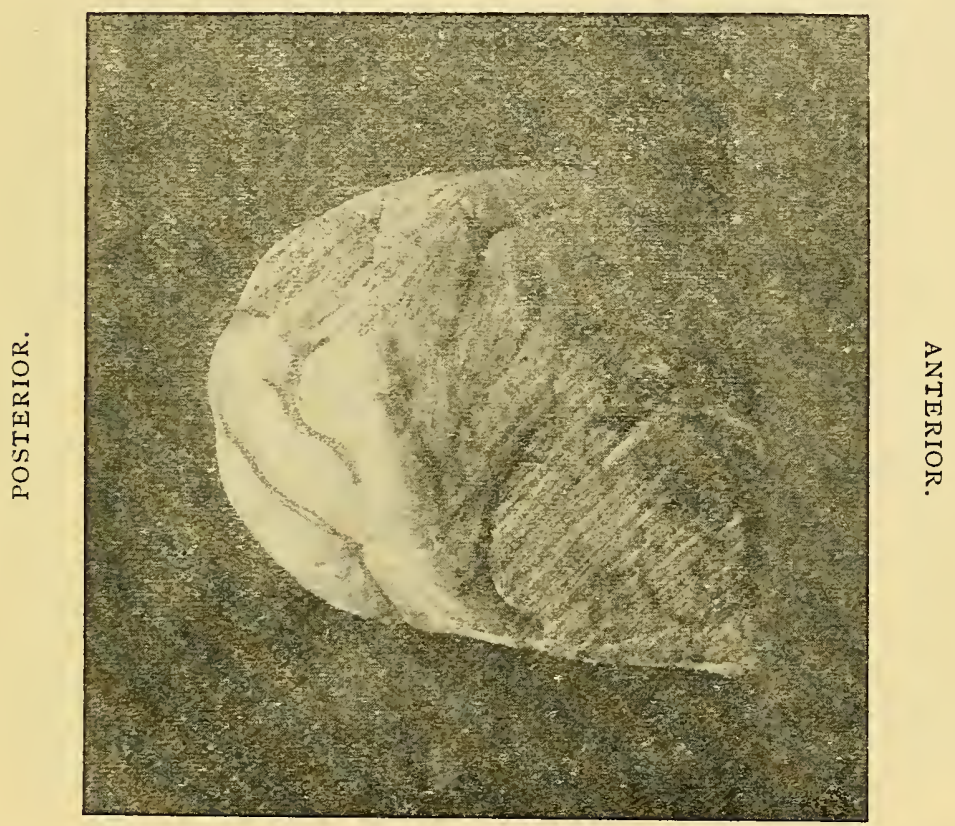

INFERIOR.

Fig. 6.-Brain of a Lamb (Ovis aries).

Left hemisphere, in part showing the occipital pole with the mental anthers or generative scrolls.

only the tongue hangs below and within, but the nostrils are lowest of all: they are in situation like the palate. Smell was called by Broca, who knew its anatomy best, the brutal sense. The lower the animal, the larger is the smell gyrus. In the brain 
of a pigmy deer, it seems a third of the whole hemisphere; while in the brain of a Parisian lady it is but a thin line, so fine you scarce can find it.

If we separate the two hemispheres of the brain

SUPERIOR.

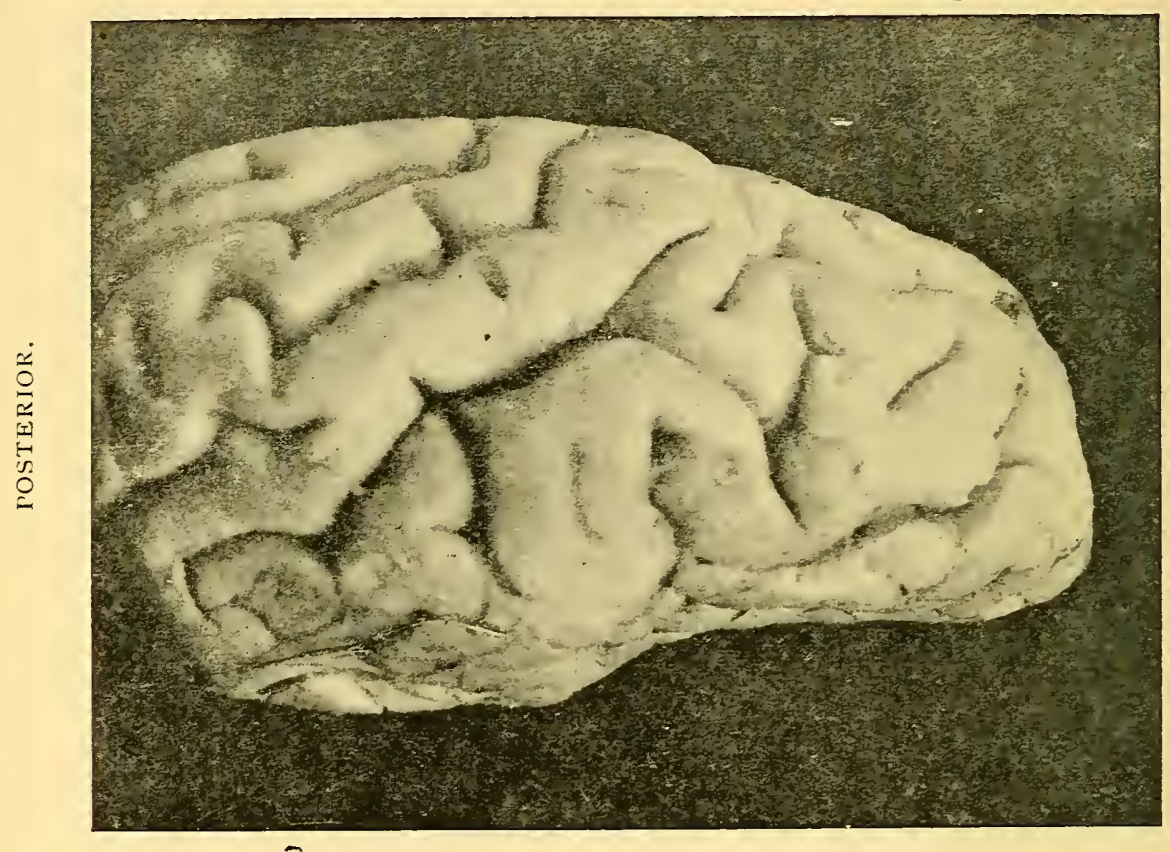

3
3
0
0
0
0

INFERIOR.

Fig. 7.-Brain of a Lamb (Ovis aries).

Side view of a right hemisphere. Posterior-superior the tactilemotile gyrus; below it the two long gyri of the eye-scroll; nearly quadrate in shape below this lies the mental ear ; superioranterior are the foot and head lobules; anterior-inferior are the arm and jaw lobules.

of a lamb, we see the psyche, as it were, in profile. The view strongly reminds one of the sagittal section of the trunk of a sheep, or other vertebrate. We distinguish at once the kopf and rumpf, the head 
of Psyche and her body. ${ }^{16}$ There are in the brain, it appears, two seats of intelligence, a kopf and rumpf, a head seat, or lobus capitalis anterior, and a body seat, or lobus capitalis posterior. One is the coronal, the other is the crown or corypheus. Thus there is an anterior and a posterior head. A lion or cat has a good posterior head, a lamb, a black-andtan dog, or a man has a good anterior head.

The posterior head cogitates realities, the anterior head cogitates idealities.

The posterior head of the lion thinks of what the lion has seen and heard, and suffered and accomplished; the anterior head of the lamb (for the lion has none worth photographing) thinks of the father, and the leader, and the shepherd, and the guide. The sheep is foolish, but he knows his shepherd, and this is the best of wisdom.

Having scrutinized the outside surface and the inside surface, having traversed the six gyri, both in their posterior and anterior direction, there remain for examination only the two poles.

One of these, the posterior, is the mental flower, the anthemion, or lignum vitæ, the genealogical tree, the seat of family affection*; the other, the anterior pole, is the reflector or concentrator, the higher psyche, the seat of attention and intention, and of insight and good-will. If one look for the higher psyche on the brain of a hyena or tiger, he had best take a lens. In the primate, on the contrary, it is long, finely arched, and typical.

* Nere York Medical Tournal, I8g6, 'A New Method in Brain Study.' . 
The Roman wolves-all Romans followed the wolf-gave the sheep the name of blockhead, Ovis

SUPERIOR.

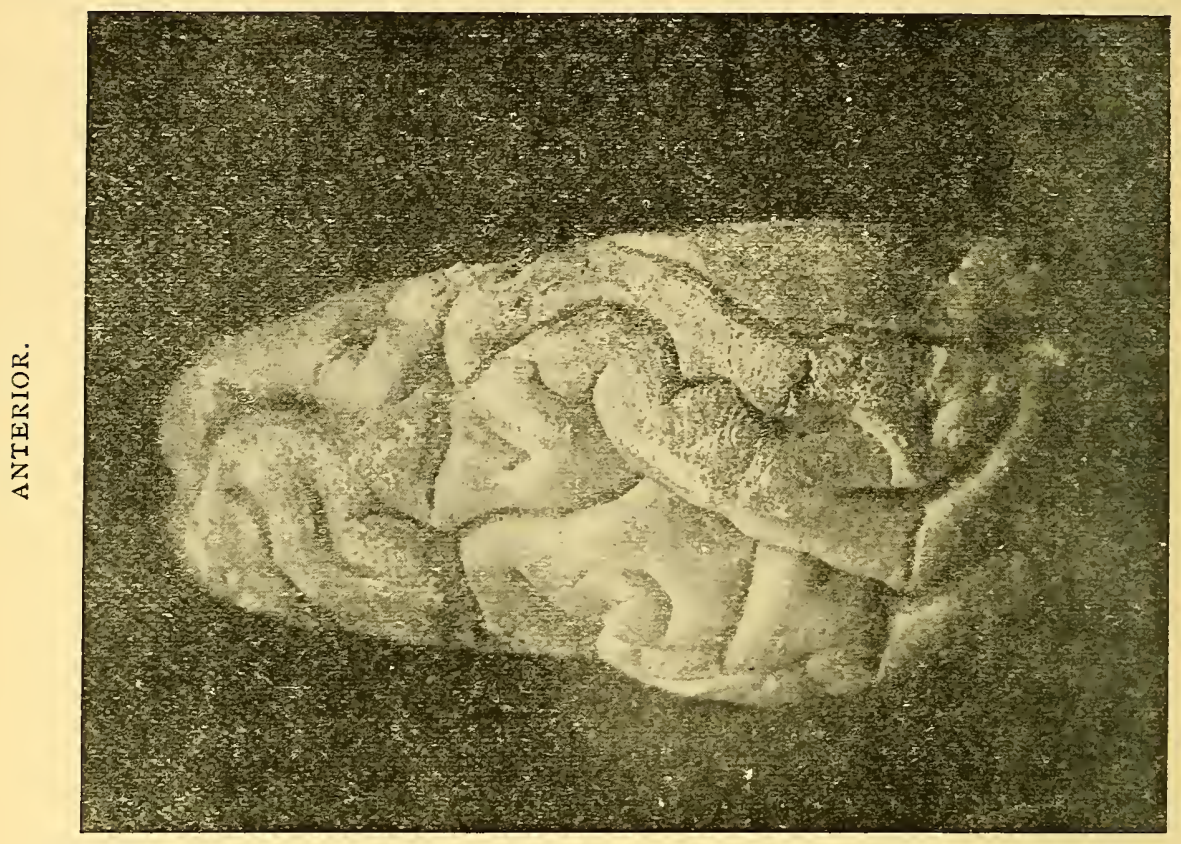

INFERIOR.

Fig. 8.-Brain of a Lamb (Ovis aries).

Left or major hemisphere, representing right half of the body. View of the top. Superior-posterior is the gyrus tactilis motilis, or posterior head (lobus corporealis); superior-anterior, the anterior head (lobus capitalis). Through the midst, sweeping. backward, is the large double eye-scroll, the occipital or receptive eye. Anterior-inferior, very small, the turn of the active or frontal eye. Inferior is the ear lobule; in front of it, doublecurve shape, is the arm. At the anterior pole are the lobules of attention and goodwill.

stolidus. The sheep is a blockhead, doubtless, and the tiger has a fine intellect--that is to say, a fine intellect posterior-that is, a sanguinary intellect; but 
in the blockhead of the lamb is a divine spark, a magic light, by which he leads the procession forward. ${ }^{17}$

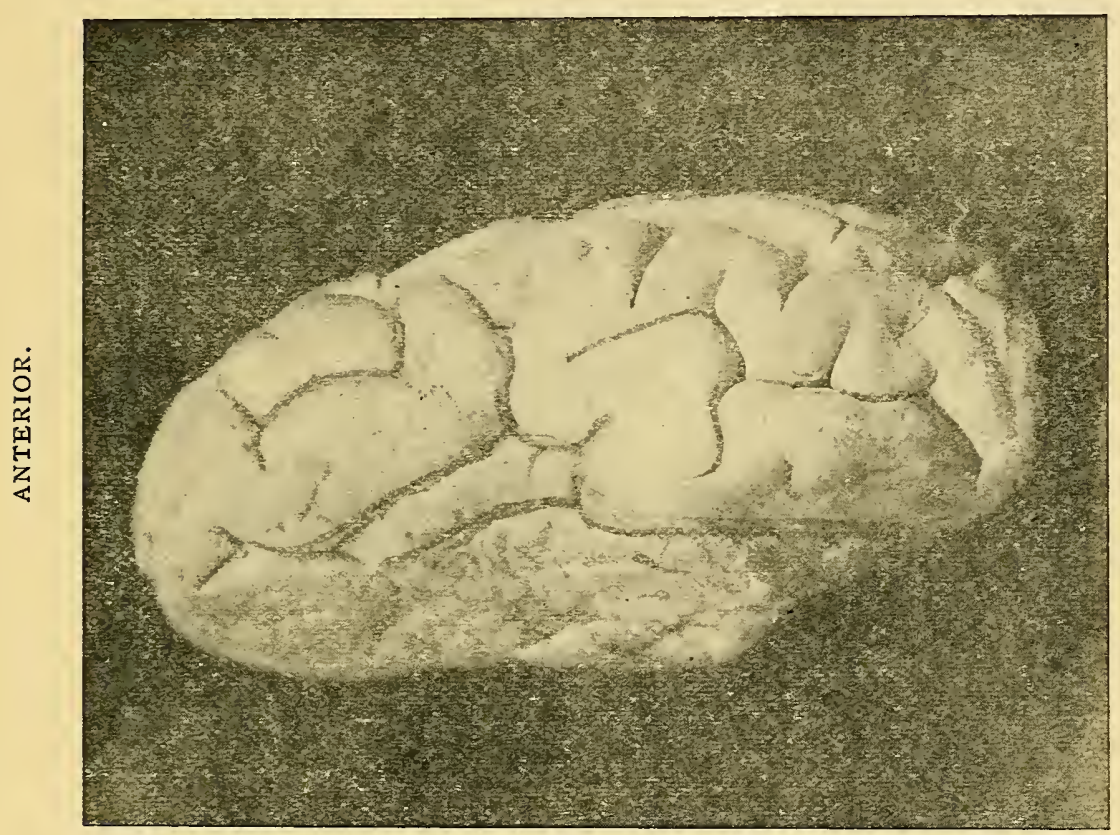

INFER:OR.

Fig. 9.-Brain of a Lamb (Ovis aries).

Left hemisphere, side view. Inferior is the smell gyrus, broad and flat; superior and slightly anterior to this is a thin rectangle, the tongue gyrus, or insula; superior-posterior to this, shaped like a crank, is the gustatory lobule; and in the opposing direction, anterior-superior to the insula, is the jaw lobule. It is arched in shape-perhaps an eidolon or image of the upper maxilla.

Let us now enumerate the lobules.

On the outside surface posterior, the mental nostril, mental palate, mental ear, mental eye, and the mental body, or posterior head. 
Anterior, the mental foot, mental arm, mental tongue and facies.

On the inside surface, the mental body and the mental head; and between them the hip and shoulder on hip and trunk lobules.

At the poles, the mental flower posterior, and the mental concentration anterior.

The soul of a lamb! Having thus passed in review all the principal points of this brain, we may now attempt a théorie cérébrale, a chart, a simple psychology of a simple soul, as follows:

I. The Sensus Fixus, the Five Senses. ${ }^{18}$

II. The activities, Going and Feeding, or Locomotion, Acquisition, and Rumination.

III. Two posterior attachments, Maternity and Sexuality.

IV. Three anterior attachments, Sociability, ${ }^{19}$ Loyalty, Paternity,* or the patriarchal sense.

V. Attention and Intention, or Idea and Will. ${ }^{20}$

* Paternity is ideal attachment, Maternity is real attachment. The mother feels she is attached to her young, the father thinks he is. Psychologists are beginning to note this distinction. Bain places Maternity first, Comte Sexuality. To these we must add Paternity, the royal affection. 
III

\section{BRAIN OF THE OX}


Psychology of Bos Taurus.

Orexis, Aisthesis, Phantasia, Kinesis, Phronesis, Boulesis. 


\section{III}

\section{BRAIN OF THE OX}

THE striking points in the brain of an ox (Bos taurus), as compared with that of man (Homo), are, first, the preponderance and convexity of the posterior half; second, the very low-pitched and elongated condition of the sensory motor lobules, that is, of the mental hip, arm, and jaw; and thirdly, the rudimentary condition of the front. The brain of man is of the frontal type, that of Bos taurus is the temporal or temporo-occipital type; the two in outline appear almost opposed.

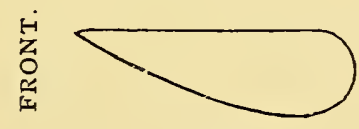

Bos.

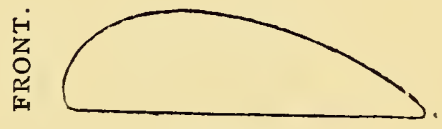

Homo.

The cerebrum of the ox is a marvel of nutritive and generative power. The greatest thing in the world is a large, strong, vigorous body. Ask the oak and ask the ox, and they will show you their mass. The greatest thing in the world is the art of propagation, and in this art also the oak and the ox win 
prizes. The greatest thing is stability, say the ox and the oak. Thus, also, say the nations that have best followed their example-the Egyptians of old, the Romans, and the modern English.

To live well, and to breed aright, and to stand fast, and to press sturdily forward is to possess the earth.

The ox brain in its posterior half shows three eminences-the temporal eminence, or the mental ear, ear-shaped, auriculate or pinnaform ; the occipital eminence, or the mental eye, scroll form; and the parietal eminence, also terminating like a scroll, pedum, or knobbed stick. The student may locate these easily. They are the cortical terminations of the auditory, optic, and spinal nerves.*

Underneath these three eminences are to be discerned three more or less sagging or crescent-shaped, always convex, lobules, so that the whole posterior half arranges itself easily in three arches and three sagmas, or undergrowths, or bases.

Inferior to the temporal eminence, then, is the sphenoidal pole or sphenoidal lobule, the stome, lobulus gustatorius.

Inferior to the occipital eminence is the occipital base, the lobus genitalis.

Between the two is the round of the region which, by its situation, would seem to be ventral or pectoral, as it is between the two others.

The three arching eminences represent to us the three heights of the ear, the eye, and back of the creature-say the ear, eye and back, rumpf, cauda, or

* The tactile and motile cogitation centre is the parietal eminence. 
ANTERIOR.

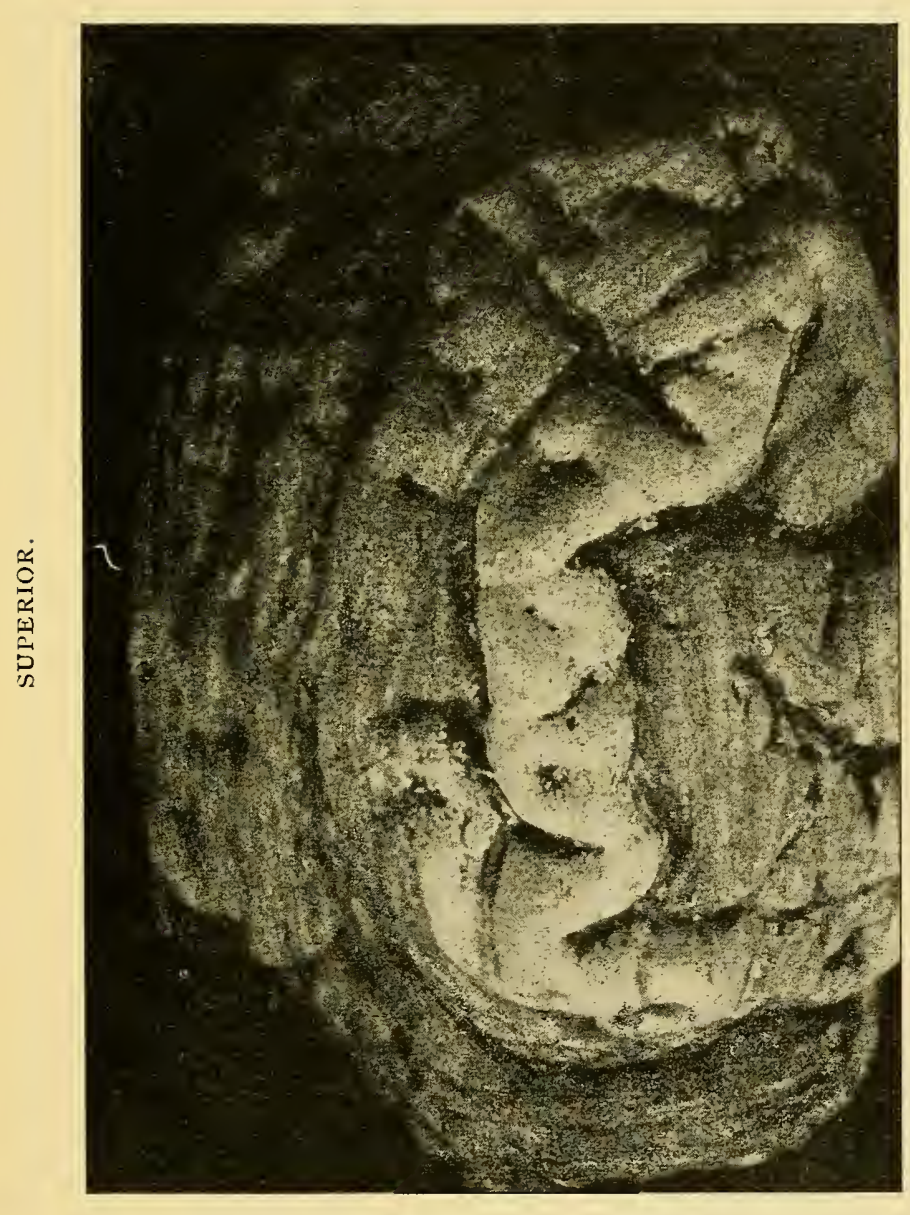

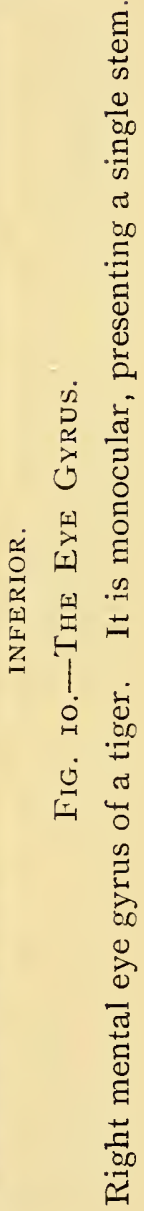

POSTERIOR, 
over posterior body of a steer. In the body all three are thrown up when the animal is excited, and the three sagmas, or convex lobules, are situated contrary to them, as the throat, abdomen, and milk-sack are situated and formed in reference to the dorsal parts.

Thus we have in the brain the spirit of the ear, the eye, and the dorsum, overcorps, on the superior aspect, and the spirit of the throat, the viscera, and the secretions on the inferior aspect. This is probable.

The six parts may be thus tabulated:

I. Parietal eminence.

Lobe of cutaneous and muscular sensibility, or lobus dorsalis.

II. Occipital eminence.

Mental eye-Visual area.

III. Temporal eminence.

Mental ear-Auditory area.

IV. Sphenoidal pole.

Mental palate-Nutritive lobe.

V. Inferior temporal lobule.

Breast-Lobulus ventralis.

VI. Occipital pole.

Secretory-Lobus genitalis.

We now turn to the anterior half, and we shall find that it consists of seven sensory motors, seven lobules, which are kinæsthetic, or contain the feelings of motion.

Lobule I., marginal, central, contains the feeling of leg motion.

Lobule II., second gyrus anterior, contains the feeling of arm motion. 
ANTERIOR.

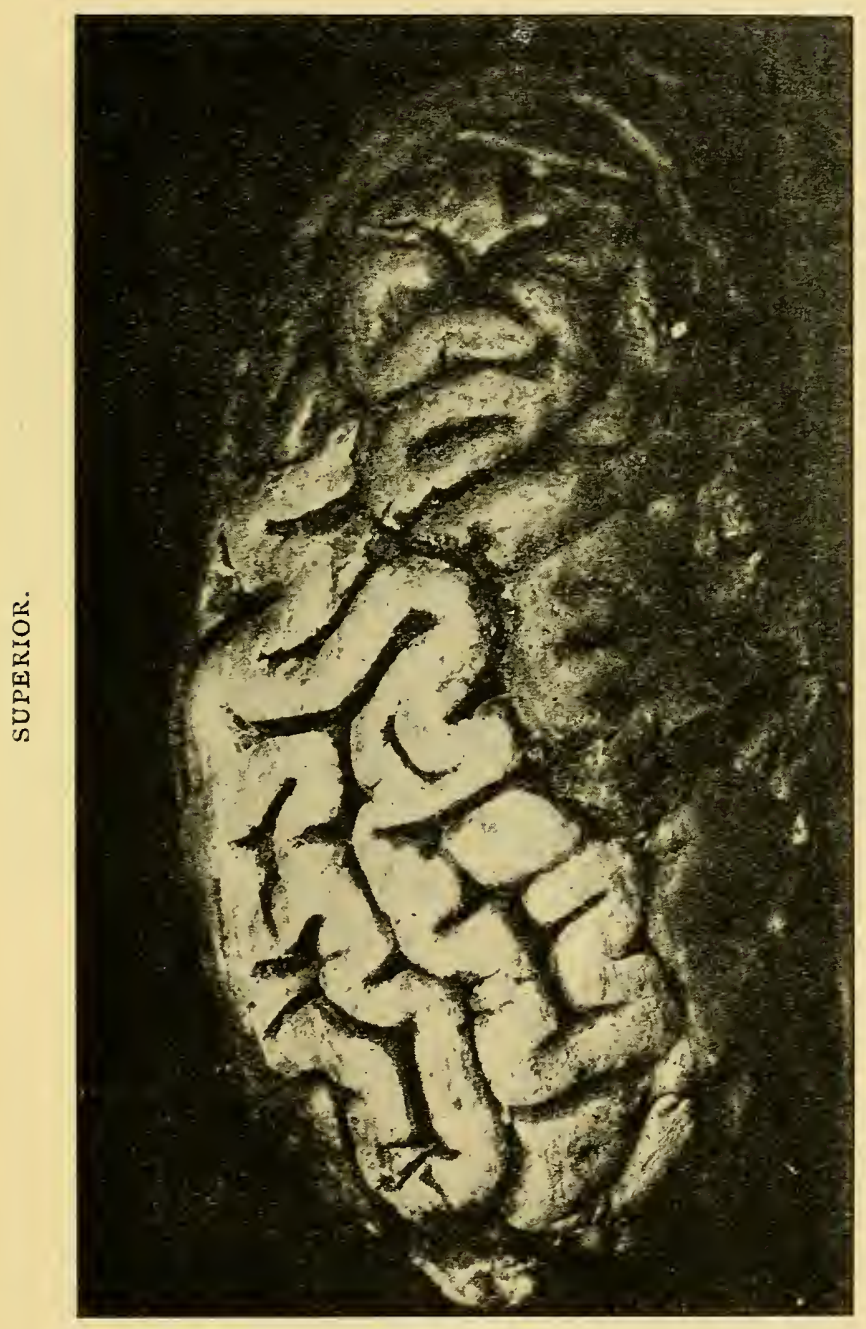

$c$

POSTERIOR. 
Lobule III., third gyrus anterior, contains the feeling of jaw motion. This lobule is concave in the lion, concavo-convex in the ox.

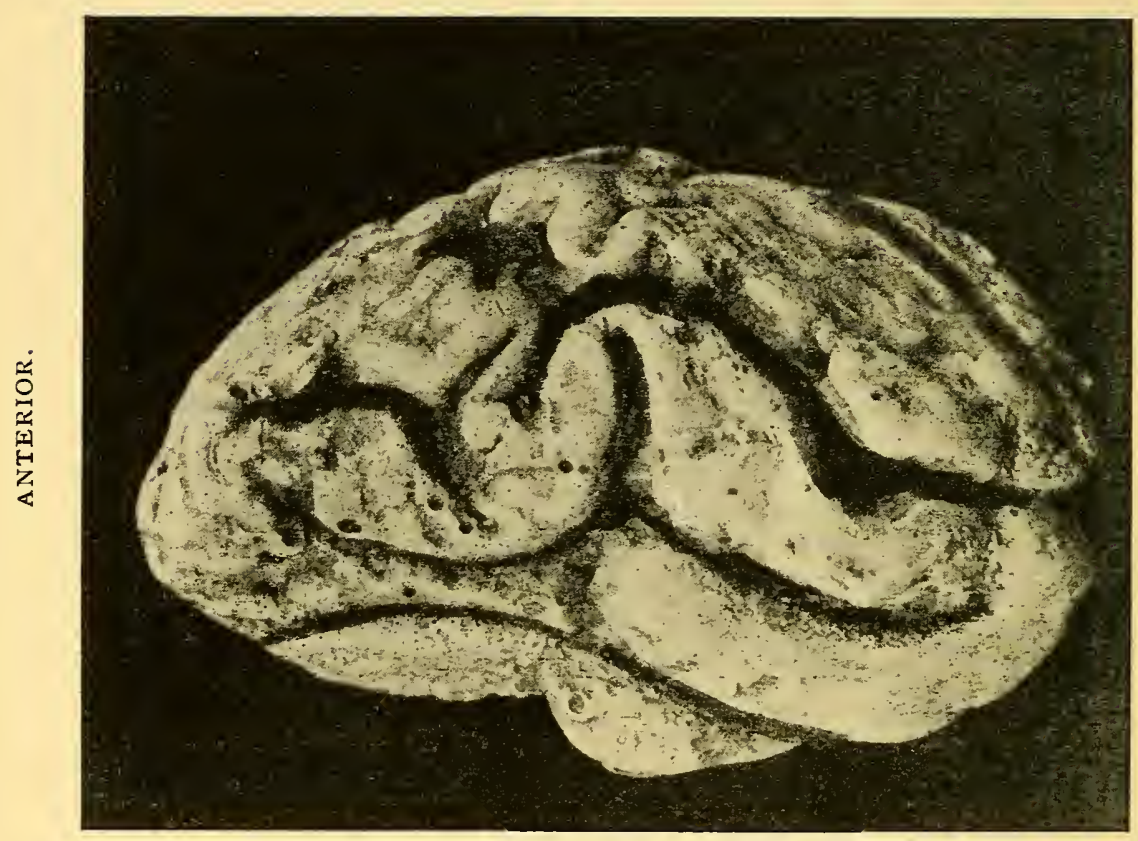

INFERIOR.

Fig. I2.- Left Hemisphere of an Ox (Bos taurus).

Posterior, one may count upward the gyri of smell, taste, hearing, sight, and body sensibility; anterior, one may count downward the pes, the manus, the miaxilla, the insula, and the smell gyrus. The lobules of the anterior pole are the head and frontal eye.

Lobules IV. and V., lobules of the forehead, contain the feelings of neck, shoulder, and head motion.

Lobules VI. and VII., situated at the ear, contain the feelings of the motions of the ear and the tongue. 
Again, three of these sensory motor lobules grow upon the first, or marginal gyrus-these contain the hip, shoulder, head feelings; one, grown upon the second, arm feeling; two, upon the third, ear feeling, mouth feeling. Action as well.

The insular gyrus is long and ribbon-like. The tongue of a cow is a long and ribbon-like feeler and tentacle, and the fourth frontal gyrus or insula in the cow is like this form in the flesh.

There remains the frontal pole.

The frontal pole consists of two lobules-the outside prow, the seat of attention or insight or intelligence, and the inside prow, the possible centre for will, intention, volition, resolution.

Table of the Sensory Motor Parts.

Hip lobule.

Pes-Lobulus clunis: Propulsion, stability, power. Sturdiness. Force of character. Arm lobule.

Manus - Lobulus brachialis : Direction, steering.

Jaw lobule.

Maxilla-Lobulus facialis: Rumination. Shoulder, neck, or trunk lobule.

Jugum: Submission, obedience.

Head lobule.

Metopon-Lobulus capitalis : Good-will and ill-will. Boulé, boulesis. ${ }^{21}$ 
One notes that the cerebral ear forms an arch, the anterior portion motor, the posterior portion auditory. One notes also that the insular gyrus is under the lobulus facialis.

We may now take a general view.

Nothing is more interesting than to note on the ox brain the position of the mental pes, manus, and maxilla, the leg, arm, and jaw lobules. Comparing them with those in our own brains, we find them very far forward and extremely low.

These lobules correspond perfectly to the very meek, lowly, humble, timorous attitude of a cow when approaching her stall. Her feet, hands, and mouth are indeed far down in the scale of being. A man is an erect intelligence. The motor lobe of the human brain is also erect. A horse-tamer can sometimes train a horse to rear upon the hind feet, but an ox will not. The feelings and tendencies of an ox are lowly; he is a true child of our mother earth. The bovine brain is the spiritual image of this feeling and attitude. To make this ox brain, this ox hemisphere, look like a human hemisphere, we should be forced to lift these lobules, the pes, manus, and maxilla, far upward and backward, which act would be somewhat like causing a hoofed quadruped to rear upon the hind feet.

Nowhere is it more plainly to be seen that the brain is the spiritual image of the life of the body than in the ox. All his bovine powers, all his bovine desires, all his bovine limitations, are there.

Here in the posterior zones are the lobules of health, vigour and valour, good appetite, sobriety. 
Here in the central and anterior $z$ ones are the lobules of strength, power, stability, steady progress, tireless industry, and stubborn defence. The ox is a born agriculturist ; nay, he is the father of the art.

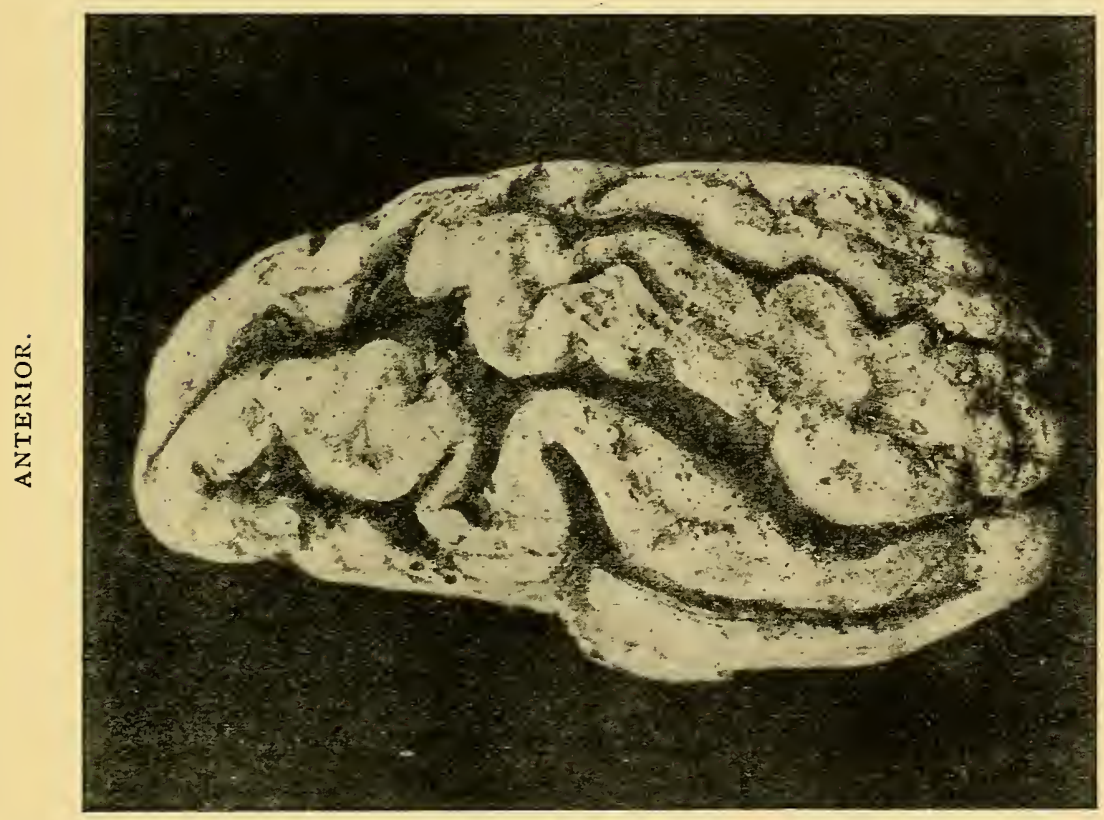

INFERIOR.

Fig. i3.-Left Henisphere of an Ox (Bos taurus).

Posterior, counting upward, are four tiers of gyri; these are lines of taste, of hearing, sight, and corporeal sensibility. Anteriorsuperior is seen the head lobule, and behind it the pes, manus, and maxilla.

$\mathrm{He}$ is the father of agriculture. As Apis, the Egyptians adored him as the founder of the permanent state. They were surely right. Without the ox and his plough, the ox and his cart, the ox 
and his threshing-floor, man might still perhaps be in the nomadic state.

The fire of life, or the power of genesis, is regarded as the first blessing of Heaven, purity as the second, and stability as the third. Stability is the third, and stability is the ox. Steadiness and regularity opposed to wildness and lawlessness, a fixed abode as opposed to roving habits, this is quite in keeping with bucolic character; the ox lends himself readily to it. As the lamb marks one epoch in the story of man, the pastoral age, so the ox marks a second epoch in the beginning of the agricultural age. 
IV PSYCHOLOGY OF FELIS 
Certain animals are gentle, slow to anger, and non-resistant Others are noble, courageous, and proud, like the lion.

Aristotle. 


\section{IV}

\section{PSYCHOLOGY OF FELIS}

HANDS, wings, griffs-which are greatest?

A child is playing on the floor; its playthings are a rattle and a kitten. Familiar associations like this do not tend to give us a high opinion of the everyday pussy; we forget that next to man she is of the most noble breed and most successful race. We forget that she is of the royal family until, by some accident, she unexpectedly and unmistakably reveals her blood; then we cry, 'What a tiger!'

If we had made her acquaintance alone, and then she had introduced us to other members of her family, a surprise would have awaited us. This is Felis pardus, the leopard, the prince of brutes, fiercest animal alive; this is Felis tigris, tiger royal, the strongest animal; this is Felis leo, the most majestic animal-Rex, regulus, the king. Tigris has energy, Leo has majesty.

The members of this royal family are very much alike: one anatomy, one physiology, one psychology suffices. You find the same ways, same spirit, humour, same heart, same soul, same brains. Their cerebral spheres differ only in size.*

* This general statement is best for the beginner. Further study, of course, reveals differences and types. 
Carnivorous life appears at first glance to be much higher than herbivorous life. It requires less courage to defend than to attack. To follow the trade of catching and killing requires sensitivity and activity, alertness and quickness, great strength and ability. When this is attained, the exploits of the bold robber and murderer quite dazzle us.

Felis is an extremely nervous animal; the vertebral column in constant motion. This, early observed, gave rise to its Greek name-Aileurus. Cats are restless, nervous, excitable animals, and, in common with simians and many insects, they have the great nervous virtue, quickness; they are 'too quick for you.' 'Did you catch it?' 'No ; it was too quick for me.' This question and answer is well understood in the animal world. To catch and not to be caught is the first law of the beast all the world over.

History gives us several names for Felis. In Egypt the name of cat and lion alike was Miow. $\mathrm{He}$ is called this because he has a pathetic and peculiar cry. It is like that of a human being.

In Hellas the cat was Aileurus, or restless-tail.

In Rome it was Felis-felicity, happiness, happy fecundity.

In vulgar parlance the name is Cat, or Scat, a name referring probably to the act of spitting at the enemy. On dit qu'il jure, and there is no reason to doubt the on dit.

The name of all, however, might well be one that reveals the secret of power and success, and tells us why the feline comes off conqueror, and why he is 
pictured as holding the world under his claw, and such a name would be the Griff, the Griffer.

Man has brains; Horse has a clean pair of heels; Elephant has a hand-nose; Simia has hands; Bos has horns and rumen; Squirrel has incisors; Felis has

ANTERIOR.

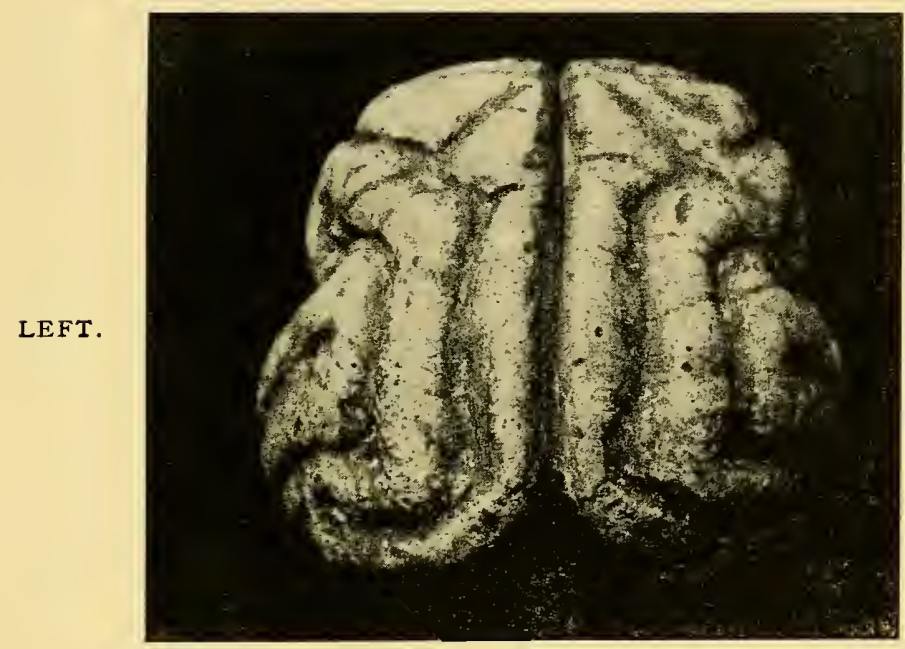

RIGHT.

POSTERIOR

Fig. I4.-Brain of Felis.

Cerebral sphere of a Parisian cat. It is extremely broad. The two side-lobes posterior are the mental ears. Over these run the pair of eye stems. The swellings right and left on the anterior half are the pair of cataclasmic dynamos, the catchers. The anterior lobe is the mental spring or spira, the psycholocnmotor. There is no appreciable forehead; the brain terminates at a point which in a human brain would be the middle.

griffes. It is the retractile clawes that have made Felis king of the beasts.

The five pair of griffs, clutches, claws, are to catch, grip, and hold. It is the hold of terror. He that clutches all things and holds all things in his grip 
and clutch, will be a successful carnivore, and gradually possess the earth-until the hero arrives with his club.**

What qualities have made the Miow? Nervousness, excitability, the moving tail, fecundity, or happy fruitfulness, strength? No frame so goodgrace, activity, agility; no frame so light-ease of motion, dexterity, adroitness. Sensitivity, sharp ears, sharp eyes, sharp nose, sharp tongue, sharp feelers, sharp tentacles, akinoia at its height. 'Be sharp,' be a sharper, be sharpest; this is the rule of the beast.

Vigilance is a fine quality. The panther wakes while others sleep. The early bird catches the worm -foolish worm! foolish bird! The day of the wise - that is, day of the lions and tyrants, day of the griffs-begins with the rise of the evening star, and not with the rise of the sun. Satan and the prince of blood turn night into day.

Heat is a fine property. The Miow has heat. Warmth is the secret of life. No animal is clothed better. Does the tiger inhabit the region of snows that, like the otter and the polar-bear, he has such fine fur? No; it is simply that he is rich and fortunate, and has found, through survival of the fittest, that warm wrappings are good everywhere. In the South there is a proverb to the effect that the wise man wears winter clothes in summer. All organisms, moreover, require warmth at night. The griffers are nocturnes.

* The club is the hero's weapon; the bayonet may be called the devil's weapon. One is overhanded, the other underhanded. 
Beauty, fecundity, eugenics, these are valuable, these are ideas useful to the race. The art of breeding, the art of breeding so as to preserve and improve the stock, to keep up perpetual strains of vigour, 'virtue,' 'nobility,' 'generosity,' preserving and im-

SUPERIOR.

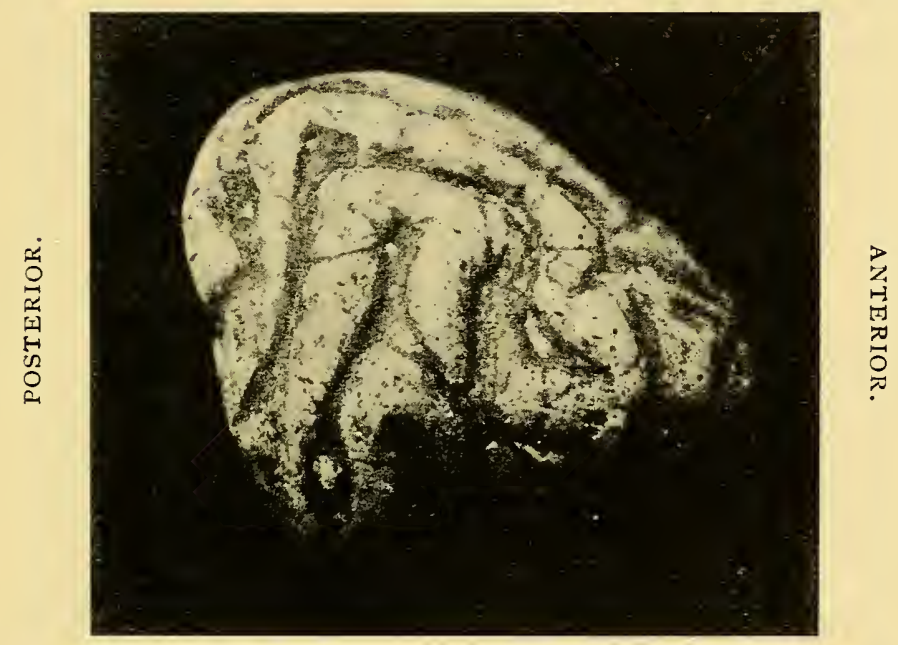

INFERIOR.

Fig. I5.-Brain of Felis.

Parisian cat, right or minor hemisphere. Anterior is the locomotor lobe. Anterior-inferior is the catcher, spirit of the face and hands; it is plough-shaped, or mandibulate. Inferior hangs the temporal under-lobe; anterior to it is seen the gastronomic area; superior to it is the temporal eminence, the cat'sear formation, the mental ear. Superior-posterior is the eye gyrus, above it gyrus of cutaneous and muscular sensibility, posterior cogitation centre.

proving all qualities, seeking the welfare of the race instead of selfish pleasure, the pleasure of the individual, this is eugenics. This happy art has the 
lion.* No flames or maternal passions are more ardent, no rivals are more fierce, no mothers are more tender, than those of the Felidæ. This insures the perpetuity of the high breed.

Three other qualities are to be added: demoniacal courage, and leonine pride, and burning wrath. The height of brutality is reached here. That a cat is the devil when he is at his worst all have agreed in all the ages, and not only this, but the worst of devilsthe head and front, the very demon, a remorseless, death-dealing force incarnate.

Indolence, too, must be taken into account. A vice? Why not a virtue? A royal virtue, surely. This quality saves one from long hours of working and saving. Let the bee work all day to gather the store of sweets; a robber, a marauder, will take all in a moment. Work? Contemptible creatures work; lions do not work. Lions recline even to eat.

It is nobler to walk than run, nobler to sit than to stand or walk, and nobler to lie than to sit. This is the true feline maxim.

Voluptuousness is a prominent feline quality. Warmth and softness, roundness, smoothness, are most agreeable to feline nature. They are agreeable to most natures.

This is in keeping with Bain's law: 'States of pleasure are concomitant with an increase of some or all of the vital forces,' a law overset in human

* Felis leo and Felis pardus appear to be a contrast in this respect. The attachments of the one are ethical, those of the other sensuous. 
brains by a higher law, and often so overset even in those of the brute.

Comparing the feline brain with that of the ox, one cannot fail to be struck with the contrast. The ox-brain is long, the other is broad. Here is

\section{SUPERIOR}

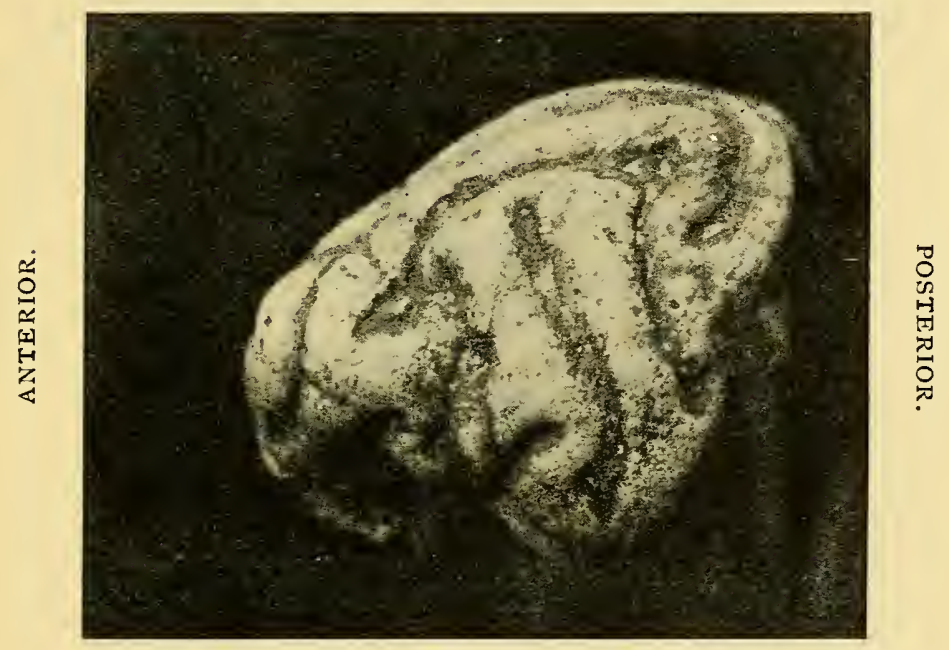

INFERIOR.

Fig. i6.-Brain of Felis.

Parisian cat, left or major hemisphere. Anterior is the sensory motor lobe. Inferior is the nutritive lobe. Posterior-superior is the eye gyrus upon the tactile-motile lobe; it is somewhat stronger than on the other hemisphere. Central is the temporal eminence, the mental ear.

the original distinction of the dolichocephalic and brachycephalic, or long heads and broad heads. One is the herbivore, the other the carnivore. The Egyptians were long-headed, industrial, and they adored the ox; the Romans were broad-headed, 
militant, and they venerated the wolf, a broad brain also.

Take now the feline hemisphere in hand. Three points present themselves at once: (I) The overcorps, or dorsum, the parietal eminence; (2) the undercorps, pectus, ventrum, under temporal lobe ; and (3) the broad and powerful lobus motoris, which is pushed far forward, and forms a globus or hemisphere by itself. One would think it the forehead. A great mistake: the cat has no forehead. No appreciable forehead, no thought lobule; no metopic lobules in the cat; these are found in the social and sagacious animals-wolf, dog, sheep, ox, horse.

Hold the brain in the hand. What are the functions of these three prominent parts?

The under temporal lobe is nutritive.

The parietal eminence is the seat of the associate tactile and motile sensibility, the personal sensitiveness, the passive or affective personality, the proud self-consciousness.

The anterior globus is the sensory motor. It pounces, catches, and kills. It is the head of wrath and destruction.

Take these one by one. The temporal under-lobe. Smell, taste, relish, hunger, thirst, restoration, refreshment, fulness, health, sickness, these must have their place. Digestion, circulation, respiration, ingestion, egestion, secretion, excretion, have their place in the nervous system somewhere. Vigour, robustness, heartiness, lustihood, the courage to undertake, where are these? Where is the spirit of the vegetative body? It can hardly be found, unless 
here. There must be an under-temporal cogitation centre, a vegetative head. Where is the struggle for life lobule? Where, if not here? Look at the breast of the body of a greyhound or a griffin; there SUPERIOR.

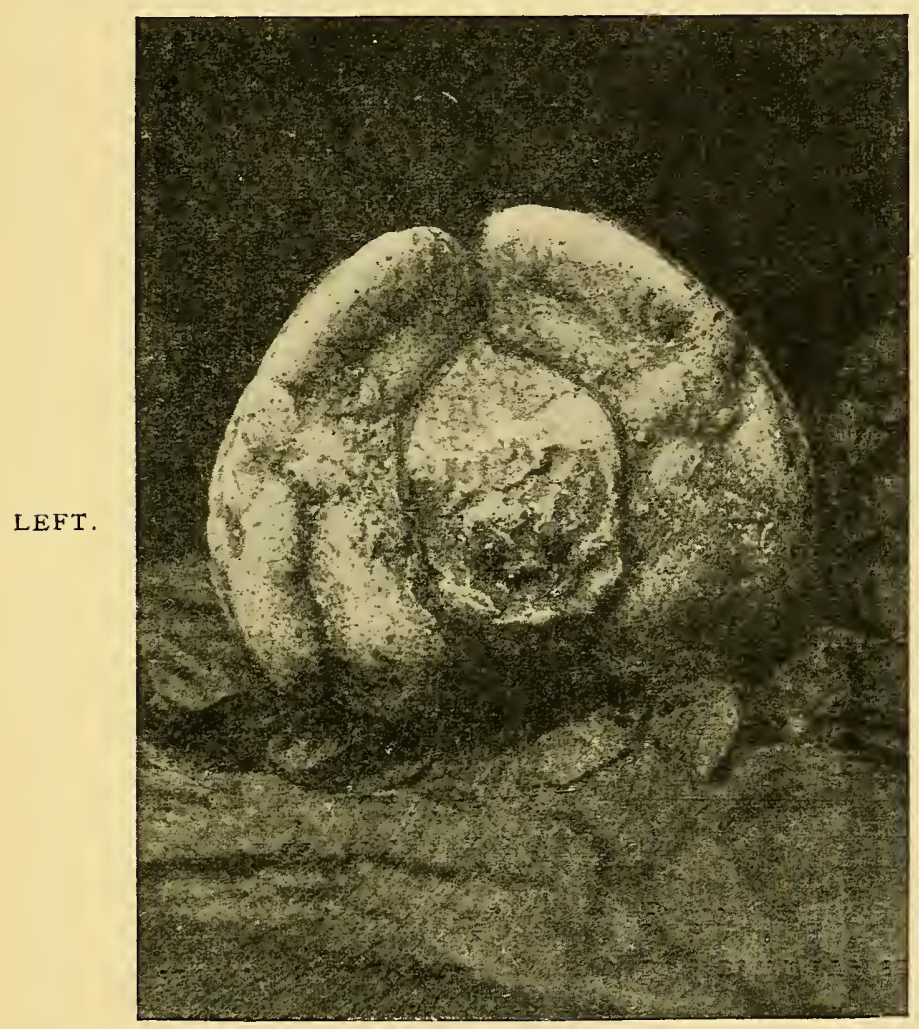

RIGHT.

INFERIOR.

Fig. I7.-Brain of Felis.

Cerebral sphere: view of the posterior, presenting the anthemion, or flower of life.

is the heart surrounded by the diaphragm and pleura, these surrounded by the ribs and intercostals, the whole forming in circles the final entrenched citadel of life. Where is the spirit, the soul of this citadel 
of life? It must be in the under-temporals. It is this temporal under-lobe that is the griffin-breast in form, and must be in spirit.

'Do not load yourself up with disheartenments and discouragements,' saith the preacher. This the Felidæ never do. 'Come, pluck up heart; let's neither faint nor fear,' quoth Bunyan's pilgrim. This good word, also, the Felidæ understand.

A heart that cannot be made to quake - where lies that heart? In the lion, in the head of every feline above all other four-footed creatures.

And in what part of the head? The temporal base.

Health and vigour, valens, valour, no disheartenments, no discouragements. Come, pluck up heart; let's neither faint nor fear. Where? In the 'breast' of the lion, in the breast of the griffin, in the pectus cerebralis of the lion, and of the wolf, and of the bull-dog, and of the domestic cat as well? We are forced to say here, 'Perhaps,' 'Probably.'

This pectus cerebralis, this temporal droop or undergrowth in the cat presents two aspects, an anterior and a posterior, and these, both in their position and appearance, look like a throat and a breast, as they also do in the deer, and in the ox, and in man.

Generally speaking, the cat is a dainty feeder, a creature of good taste, non-swinish. Thus, the anterior or palate portion is clear-cut, neatly developed.

In comparison with dogs, the feline shows refined taste.

Turn now to higher parts.

The cerebrum is a mechanism. The anterior half 
of the cat's cerebrum may be considered in two parts, an over-lobe and an under- or side-lobe. The over-lobe is more the locomotor, the side-lobe is more the catcher and killer.

By comparing the top of the anterior lobes of cat and fox, or tiger and wolf, one may see the difference in the formation of the top lobe-one the running locomotor, and the other the leaping locomotor. The latter is like a spring wound up higher than the former; the gyres are folded tighter. In the lion and tiger vehemence reaches its height. Sensationalism knows nothing equal to the springing of the cat upon its victim, the tiger upon its prey.

The catcher, or pair of side-lobules in the cat forehead, is extremely broad, as it is also in that of the bull-dog. Breadth here appears to mean destructive force. The bull-dog's bodily conformation shows this by the breadth of jaw and breast, giving him the typically ugly appearance. In the same way the exterior forehead of the tiger or tiger-cat has the typical low, broad, flat, excessively ugly face. Nothing can exceed the brutality of it, and we trace the peculiarly flat, low, broad, ugly shape when the skull is removed, and find that the spirit of it is a compact, screw-plough or plough-screwshaped lobule, a terrible spiritual engine, the destroyer; not the destroying angel, but the destroying demon.

Homo is the angel, Felis is the demon. These are their types.*

* A London critic wished that Tennyson, as seen through his biographer, had less of the archangel and more of the tiger-cat. The study of psychology leads us to prefer the archangel. 
Felis has the best mental ear in the world. Both eyes and ears are remarkable, but the cerebral ear dominates the whole side of the head-the posterior hemisphere-as the catcher and killer dominates the whole of the anterior hemisphere. The hearing of a lion or tiger would perhaps seem to us, if we could know it, something supernatural.

One that has observed a cat watching the hole of a mouse will note that the cat is not watching with her eyes alone, but with her ears. The ears are the secret of success; the catcher that waits until the prey is in sight will lose it. The ear trained through ages by the solemn stillness of the night-watch must be peculiar. The tyrant should hear all that is said of him. Eternal vigilance is the price of tyranny.

Felis has also a remarkable eye-that is, a nocturnal eye. The mental eye in the feline brain is built of a single shaft, terminating in an arrow-head, or hammer-head. This eye-shaft is rather straight. In man it lies in peculiar folds-i.e., convolutions-yet both alike have but a single stem.

One is surprised to find that the feline type resembles man, and is the contrary of that of sheep, ox, wolf, horse, deer, etc., and that the eye of the dog goes with these.

The fact appears that men and cats are the only animals that do not run. Is the statement rash? Say, then, felines and primates are non-celeres. Both cat and monkey climb a tree. Neither felines nor men are swift.

Other creatures escape by running. Man and the lion generally face each other. Neither of them is 
inclined to run; it is not their way. Horses are swift, deer run, wolves, hounds-these are the celeres; cattle, too, sheep, swine, goats, all are fond of locomotion. Felines and men-men and lions-do not run. One stands, the other bounds.

We find now that all the celeres-that is, the animals that escape or pursue by running-have cerebral eyes with compound stems. The eyestamen of Canis and Ovis is double, that of Bos double or triple, that of Equus--the horse-double, triple, or quadruple. Now, these wide-open, widegazing eye-gyres in the brain must correspond to speed, swiftness, the needs of the celeres and the pursued. The pursued must see even better than the pursuers; they must avoid obstacles.

The mental eye of a cat apparently is one straight, concentrated beam. It is a well-arranged, quickmoving reflector. In man, this pathway is single, but very much curved, folded. The ray may traverse many folds of memory before it passes on and strikes the motor, determining action. Nevertheless, the eye in man and lion is of similar type in so far as it appears single-shafted. That of the horse is the strongest contrast to both alike.

Noting the most prominent parts of the brain of a lion, we may provisionally call them as follows, giving the language or spirit of each:

The cerebral dorsum ... Personality, pride, selfconsciousness. ${ }^{22}$

The cerebral ventrum ... Non-discouragement, nondisheartenment. 
The cerebral ear ... Vigilance. The 'supernatural. ${ }^{23}$

Cerebral claws and jaws Effective wrath. The cerebral eye ... Luminous intensity. The cerebral tongue ... Taste.

The anthos $\quad \ldots \quad \ldots$ Ardour, felicity, fecundity.

Let us compare the Felidæ and man. The Felidæ are next in force, but contrary in feeling. In force, ability, faculty, felines stand next to man. Nevertheless, the feline is his antithesis.

Next to human or primate hands come feline griffes, but the griff is the contrary nature-a clutch, a grip, a hand of torture.

Next to the human voice comes the feline voice, but it is the contrary-a painful cry.

Next to human eyes comes the feline eye, but it is the contrary - a straight, killing eye, and a night eye.

Felis and man are non-runners, but contraryman stands, the feline springs.

'Men and tigers rule the world,' says Felis.

Man stands and holds with his hands, Felis catches and holds with her griffs. Hands and griffs rule the world.

Hand is the angel, Griff is the demon. Hands, wings, and griffes, which are greatest? Let the lion answer, and let man answer. 
The following are feline qualities:

Pride, amour propre.

Dignity. ${ }^{24}$

Irascibility, short temper.

Indolence, love of ease.

Voluptuousness.

Ardour, in rivalry and maternity.

Vigilance, the habit of the night-watch.

Activity.

Sensitivity.

Quickness.

Dauntlessness, cour de lion.

Taste, 'generous living.'

Tact, management, ability.

Independence, unsociability.

Pathetic or human-like voice.

Felicity, perfect adjustment as to food and progeny.

Slyness, the 'slinking' habit.

The spitting habit. On dit qu'il jure.

Vehemence, strength of the mid-soul.

Previousness, getting the grip or clutch ahead of everything.

Nocturnal or superhuman vision.

Tyranny, the tyrannic passion.

Might. La force prime le droit.

Smallness of forehead. Man has the largest, the tiger has the smallest soul. 



\section{V}

THE BRAIN OF MAN 
Noble be man,

Helpful and good!

For that alone

Distinguisheth him

From all the beings

Unto us known.

Hail to the beings,

Unknown and glorious, Whom we forebode!

From his example

Learn we to know them.

Gocthe. 


\section{V \\ THE BRAIN OF MAN \\ Lobules OF THE Mind}

THE student in the Cerebrological* Institute will be taught first to prepare, with proper chemicals, the cerebral sphere of a sheep, to model it in wax, to take six or eight photographs of it, and to make six plaster-casts. Upon these he will paint in colours the lobes, the gyri, the lobules, the scrolls, and the centres.

The brain of the ox will next be treated in the same manner.

By these preliminary studies one becomes somewhat familiar with gyrotechnics, and learns the position and form of the principal centres.

The cerebral lobules, with the exception of three or four, such as the talking lobule, the writing lobule, and the centres of the functions of the spirit are found in a rudimentary form in the cow and sheep, and may be identified in the human cerebrum, where they show an extraordinary development, and become complicated and difficult.

Taking a human hemisphere in hand, one may first note the four poles or primary lobes: the frontal, the parietal, the temporal, the occipital.

* Gr. кápa, the head. 
The frontal is the seat of reflection and expression, the parietal is the head of motion, the temporal is the seat of audition, and is the head of nutrition, the occipital is the area of vision and head of generation. ${ }^{25}$

One may next take note of four important fissures, which are the following, easily found:

The superior and inferior frontal fissures.

The fissure of Sylvius and the fissure of Rolando.

The parietal fissure and the superior temporal fissure.

We may next note the principal gyri or convolutions of the outside surface. These are best observed by threes.

FRONTAL REGION.

The superior frontal convolution.

The middle frontal convolution.

The inferior frontal convolution.

PARIETAL REGION.

The pre-central convolution.

The post-central convolution.

The parietal-marginal convolution.

OCCIPITAL REGION.

The superior occipital convolution.

The middle occipital convolution, with the pli courbe or eye-stem.

The inferior occipital convolution. 
TEMPORAL REGION.

The superior temporal convolution.

The middle temporal convolution.

The inferior temporal convolution.

With these landmarks fixed, one may begin observations upon the under and outer surfaces. ${ }^{26}$

The posterior portion of the cerebral sphere is sensational, the middle is the sensory motor, the anterior is reflexional and expressional, the rounded front being the high psyche. This is largest in man and woman, smallest in the tiger.

Five senses, three actions, and three frontal activities are to be considered.

Olfactory, gustatory, auditory, optic, and sensitive impressions are constantly projected upwards into the posterior portion, the receiver. This posterior is the anima patiens, the passive soul ; it is the affective zone, filled with pathemata, experiences.

Streams of active spirit are running down from the strong central zone, the motor, animating the members-that is, driving the three spiral mechanisms, the legs, the arms, the jaws. This zone is the anima agens, the effective sphere; it is the kinestheticon, filled with feelings of action.*

Talking, writing, and high thinking are frontal activities. Here is the anima fulgens. ${ }^{27}$

The posterior of the brain is sensational, and also impulsive. Upon the posterior half of a human

* 'It is a motor' (Ferrier). 'The fuhlsphere' (Munk). 'It is kinæsthetic' (Bastian). 
hemisphere one will find three lobules beneath and three lobules above: the under three belong to vitality and to impulse, the over three to sensitivity. The under surface is the seat of gustatory, visceral, and genital sensibility; the over surface the seat of ear sense, eye sense, and the personal sensibility, associate tactility and motility.

The lobules of gustatory, visceral, and reproductive sensibility together form a shape like a griffin or hippocampus, of which the sphenoidal pole is the mouth or stoma, the under-temporal lobule the pectus, and the under-occipital the cauda.

Above these rise the temporal eminence, the latero-occipital eminence, parietal eminence; they rise in the same order and position as in bovines and felines and other mammalia.

The ear lobule is more or less auriculate in shape; the lobule of visual sensibility is a scroll formation, a single shaft terminating in a scroll, in which one finds the cuneus, the cortical retina;* while the parietal eminence or parietal lobule appears as a kind of frog's-leg formation, having three gyrules, very much shortened up, wonderfully compact and crowded when compared to the same lobule in the ox or lion, or that of any quadruped.

The form of the parietal lobule is suggestive of the posterior of a frog at rest, and is also suggestive of the form of a pelvis.

Anterior to the six lobules of sensibility lies the Rolando region, the 'fuhlsphere,' the grand motor.

* The whole occipital lobe in the human brain in form resembles the 'pope's nose,' or ouropygium of a fowl. 
It is a triple spiral ; it is the cerebral pes, manus, and maxilla. These are the leg, arm, and jaw lobules, or the mental hip, arm, and mouth. Through the midst, like a river, runs the fissure of Rolando. The whole formation looks like a great river descending through the midst of the hemisphere. It is the region of motor feeling and descending currents.

Some anatomists have marked the Rolando tract thus :

I. Fissure of Rolando, or central fissure.

2. Precentral gyrus, anterior to the fissure.

3. Postcentral gyrus, posterior to the fissure.

4. Paracentral gyrus, above the fissure.

5. Infracentral gyrus, below the fissure.

In front of the motor one traces two horizontal fissures and three very important gyri:

The superior frontal gyrus.

The middle frontal gyrus.

The inferior frontal gyrus.

These are the head lobe, the eye lobe, and the speaking lobe. The function of the first is attachment, or goodwill, or fervour; that of the second ideation, insight, or imagination-it sees the invisible ; that of the third motor speech-it understands and speaks.

Each of these three frontal lobes or gyri may be taken in three parts. We may at first, however, note only the two anterior parts of each. 
The superior frontal shows head lobule and trunk lobule.

The middle frontal shows the visual lobule and the graphic lobule.

The inferior shows cap and pied, or head and foot, of the lobule of motor speech, discovered by Broca. Of this talker, or lobulus loquens, one sees that the one part, the passive, pars passiva, is triangular-shaped, or like an earlet; and the other, the pars activa, is elongate, or like a tonguelet.*

Beside these are three lobules: the prorean, the orbit, and the sub-prorean, three points of culmination or concentration. We note the salience, a small, but very prominent, lobule appearing to be a junction of the second and third frontal gyri. This is a possible centre for the 'logos.' The insula is hidden under the speaking lips and the expressional lips of the infra-central gyrus.

Having noticed these eighteen parts on the exterior, the hemisphere may be turned over. Here we shall find old friends with new faces-that is, some of the same lobules in another aspect. On the inside surface one may trace first the sweep of the great arch or belt, fornicatus, cingulum, which connects with a shortened, compact lobule posterior, forming the quadratus or precuneus, a portion of the parietal lobule and the seat of muscular and cutaneous sensibility and associated sensibility-a region of great importance. Note that the gyrus

* The third frontal convolution is often divided into four parts : the pars basilaris, pars ascendens, pars triangularis, and pars orbitalis. 
fornicatus, the quadrate lobule, and the parietal lobule appear to unite in one vast tract or zone-the posterior cogitation centre. This is, as it were, an anti-forehead, a posterior intelligence.

Posterior to the quadratus is the cuneus, or point of the occipital eye-scroll. The eye-scroll is actually folded over in a most curious way. Inferior to the cuneus is the anthos, or flower of reproductivity; it consists of three or four ramps or anthers. Two of these are named the lingualis and the fusiformis. This lobe is the fountain from which flow the tender feelings.

Looking next to the more anterior portion, the superior gyrus is called the marginal. It is broad, rather square, a noble arch. One notes upon it a well-marked oval lobule, the paracentral. This is the head of the Rolando region or the motor. It is the pes, or mental hip. In cases of chronic mania this lobule becomes permanently exalted or salient. ${ }^{28}$

This lobule is easily found in all brains. In man it is farthest back, in the tiger farthest forward.

The next lobule in front of this is the anterior metopic, the mental neck or trunk; and still further anterior is the head lobule, the seat of attachment, goodwill, willingness, fidelity, loyalty, humanity. Underneath it anterior is the prow, the possible seat of the $\beta$ ou $\lambda \eta^{\prime}$.

This prow lobule presents two parts, the gyrus rectus inferior and the rectangle superior. The rectangle is the point of junction between the first and second frontal gyri. It is best studied in the sheep or ox, where its formation is more simple.

$$
6-2
$$


With these anatomical data one may venture to tabulate the eighteen cerebral lobules, an arrangement tentative and provisional, something as follows :

Of the combined outer and under brain surfaces we draw a simple schema, with enumeration of the lobules, thus :

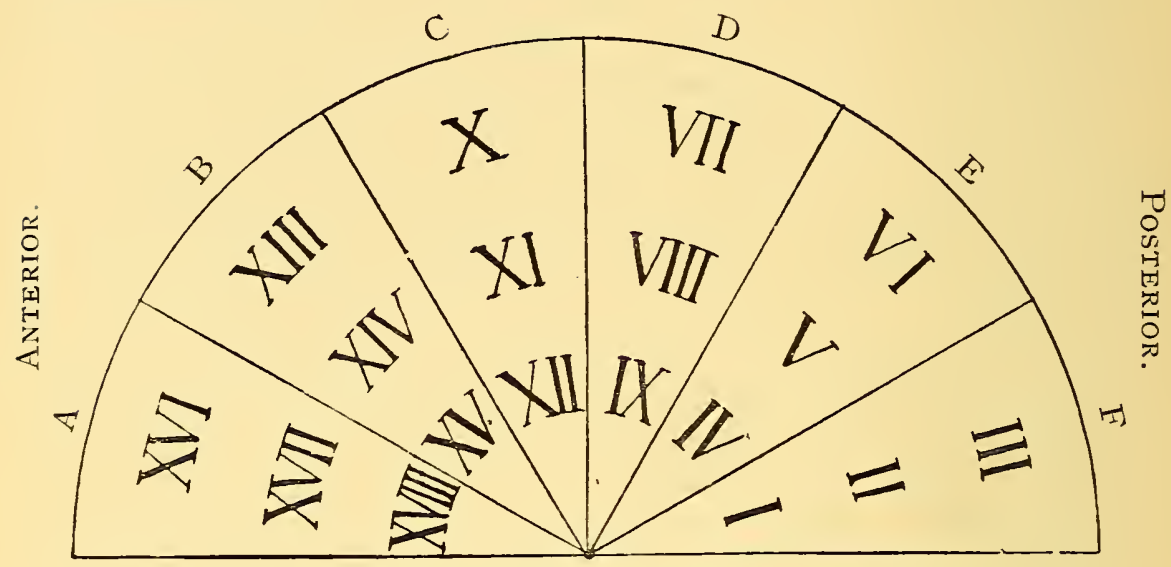

I. Gustatory sensibility-sphenoidal lobe.

II. Visceral sensibility-under-temporal lobe.

III. Genital sensibility-under-occipital lobe.

IV. Auditory sensibility-temporal eminence.

V. Visual sensibility-latero-cccipital eminence.

VI. Muscular and cutaneous sensibility-parietal eminence.

VII. Pes, leg motor-superior central.

VIII. Manus, arm motor-middle central.

IX. Maxilla, mouth motor-inferior central.

$\mathrm{X}$. Mental neck or trunk-posterior metopic lobule.

XI. The writing centre-foot of second frontal.

XII. The talking centre-foot of third frontal.

XIII. The head-anterior metopic lobule.

XIV. The frontal eye-head of second frontal.

$X V$. Cap, or head of the talking centre.

XVI. The under-prora-gyrus, rectus, etc.

XVII. The prora-the coil or rectangle.

XVIII. The orbit. 
Following, then, is a summary of the activities of the cerebral sphere in man. The numbers correspond with those on the key-plan of the brain on the previous page.

\section{I.-Nutritive Feelings. \\ The Sphenoidal Lobe.}

Smell: Scent, odour, fragrance, freshness, purity.

Taste: Relish and disgust, sweetness, bitterness, acid, piquancy, flavour.

Internal warmth, refreshment, restoration.

Hunger: Thirst, appetite, satiety.

Longing, desire, want.

Orexis, epithymia.

The gastronomicon. Gustatory feelings.

Memories of odours and savours.

Appetite and repugnance, desire and aversion. ${ }^{29}$.

\section{II.-The Vital Feelings.}

Under temporal Lobe. Visceral Sensibility.

Negative: Disheartenment, discouragement, weakness, 'sick at heart,' hypochondria, melancholy, mental invalidism, depression. Atrophy.

Positive: The stout heart, health, validity, valour, struggle, fulness of life, vigour. The strenuous lobule. The love of life. Self-preservation. Defence.

Exaltation of the spirit of heart and lungs, joie de vivre, spirit of ox, elephant and all robust animals, vis vitalis, vegetative strength and hardihood, lustihood ('hearts of oak'). Lobus robustus. Lobus vitalis. The temporal cogitation centre. ${ }^{30}$ 


\section{III.-The Tender Feelings.}

Occipital Attachment. The Under-occipital Lobe.

The Mystery. The fire of new life.

Maternal feelings. Desire, purity. Modesty.

Functions of marriage and parentage.

Instincts of maternity and conjugality.

Storge, Eros, Aphrodite, Philostorge.

Love, beauty and birth. The pur technicon.

Family affection, ' bowels,' splanchna, yearning.

Clinging together of father, mother, sister, brother, wife, husband, and children. The heart.

Ardour, inflammability.

The vernal impulse. Participation in the eternal.

Desire to reproduce one's self. The anthos.

Desire to possess beauty; passion to unite one's self to beauty; desire to reproduce one's self in beauty.

The anthemion, the caduceus, the clavis vita, the anti-death lobe. The lignum vita, the tree of life. The sepulchral form. The hope to avoid death.

The under-occipital lobe is the home of the antique graces, as the forehead is the home of the Christian graces.

The sacred fire. Heart of the flower. Fountain of the tender feelings, and of the mystery of life and death. Primary passion and source of all others. ${ }^{31}$

\section{IV.-The Ear Sense.}

The Temporal Eminence. Ear Sensibility,

Ear Memories.

The mental ear. Auditory representation. Audition, feeling for music, sensitiveness to noise. Memory of sounds and sequence, memory of words, conversations. 
A person having a good ear memory is called an audile; one with a good eye memory is called a visile. Felis is an audile, Canis is a visile.

Arrectis auribus. Auditory, auricular, acoustic lobule. The acousticon.

Feeling for melody, concord, rhythm, rhyme, harmony, measure, sequence, time, tune, pitch, symphony, concert. Appreciation of music and poetry. Memory of spoken words.

Excellence of this lobe is a good ear, an acute ear, a sharp ear, a correct ear, a nice ear, a delicate ear.

Tasmit is goddess of hearing, a personification of the mental ear.

Thirst for knowledge, desire to hear.

\section{V.-The Eye Sense.}

Over-occipital Lobe. Mental Eye of the Occiput. Cortical Retina. The Eye of Memory.

Feeling for light, colour, lustre, variegation, for forms, decoration, sensuous beauty. Phantasie.

Memory of sights, colours and the concrete.

Memory of written words. Passive imagination.

Memory of diagrams, forms, figures, faces.

Greeks and French have remarkable mental eyes; Hebrews and Germans have remarkable mental ears.

Perception of light-morning light, noonday, afternoon light, moonlight, darkness, shadows.

Appreciation of physical beauty, love of red or bay, black, white, tawny or fawn, spots and stripes. Birds and insects appreciate bright and metallic hues, the mammalia do not. 
Appreciation of the nest or concavity, as lap or bosom, and of the round or convexity, the handsome or well-turned limbs, and of the graceful, or slender. Fascination. Obsession.

Curiosity, desire to see. The opticon, register of all things seen. Visual representation.

\section{Vi.-The Personal Feelings.}

Sensitiveness. The Parietes. The Double Parietal Lobule. Posterior Cogitation Centre. The Posterior Conscionsness. Parietal Eminence.

This is a large lobe of cutaneous and muscular sensibility, a centre for cogitations of one's own experiences and personality. From pathemata come mathemata. Experience is the best teacher.

Feelings of hurtings and caressings. Sensitiveness to pleasantness and painfulness. Patheticon. Hedonicon. Esthesion. Algedonicon.

Feelings of warmth and softness, roundness, smoothness, ease and lightness, and their contraries.

Feelings of self-love, self-consciousness. The lobe is full of personalities. It is the point of honour, the soul of the seif. Pride. Fierté. Superbia.

Sensitiveness to praise and blame. Queenliness, the lobule that wears the blushing honours.

Lobe of self-consciousness.

Philoproteia. The love of being first, the prince, the leader, the Coryphæus.

Thirst for fame. Ambition, emulation.

The conscience. Memory of the evil and the 
good, and of punishments. Seat of remorse and regret.

Posterior superior inclination.

Joy and sorrow. Irritability. Hyperæsthesia..$^{32}$

\section{VII.-Motor FenLings.}

Paracentral Lobule. The Pes. The Mental Foot.

This lobule is power in the horse, stability in the ox, vehemence in the lion, persistence in the wolf, and violence in the maniac.

Power, stability, persistence, royalty, command, aggression, vehemence. The 'Temporal Power.'

Pursuit, love of racing, love of the chase.

The domineering spirit, hauteur, despotism, tyranny, the trampling disposition. The ruthless lobule.

Feeling of might and majesty, the dictator, the imperator, the podestat, the dominus, the driver, the charioteer. Desire to drive.

Spirit of the throne and the sceptre. Ambition.

Spirit of the cavalier and the equestrian order, spirit of the statue, the statue of the emperor.

The tyrant. The talon, the iron heel.

Conquest. Triumph. Victoria.

\section{VIII.-Motor FeELINGS.}

Medicentral Lobule. The Manus. The Arm Centre. The Mental Hand.

In quadrupeds this is the steering lobule. In man it is the animus inciting to every kind of manual labour, destructive, constructive, operative. 
Tact, management, adroitness, dexterity.

Power of the hands, power to do. Ability, feeling of ability and inability.**

Lobule of awkwardness, lobule of excellence, consciousness of educated or uneducated muscle.

Executive ability. This lobule prominent in the Romans. Enormous in Augustus Cæsar.

The ability to make and to do.

The strong arm. The strong hand. Main force. Cæsar's hand.

Efficiency for self and others.

\section{IX.-Motor FeELINGS.}

The Maxilla. The Mental Jaw. Cerebral Facies. Lobule of Temper, both Good and Bad.

In the cerebral facies is the spirit of mastication, eating, taking, appropriating.

It is also the spirit of biting, crushing, gripping, destroying. Also contrary, kiss of affection.

It is the lobule of hate, but also the contrary or smiling good-nature. Lobe of facial expression.

Feelings of biting or bitterness. It is the lobule of faults of temper. Seat of anger, of irascibility.

Lobule of placability and implacability.

Short temper, quick temper, hot temper, and their contraries. Destructive instinct.

Rage, wrath, the burning wrath of Achilles finds outlet here; a towering rage begins in the facies

* The malady of aboule, or enfeebled will, is not yet located. It is probably in the prora, as the prow is believed to be the centre of control. The trouble may be in the motor, however. 
or mouth lobule, towers up the fissure of Rolando to the manus, and thence to the top, the pes; from this it descends cataclasmic, convulsing body, arms, face. It is an epileptic seizure.

A fit of passion may also take the contrary direction, that is, pes, manus, maxilla, or 'chase, catch, kill.' ${ }^{33}$

X.-Feelings of Submission and Aspiration.

Posterior Metopic Lobule. Trunk Lobule. Jugum. Ala.

The trunk, neck and shoulder lobule may be the contrary of the hip and leg lobule (that is, the paracentral), its function submission, as that of its neighbour is domination. Pantomime. Mimeticon.

This lobule appears to rise on the horse, sheep, cow, and some dogs. Mansuetudo. Adulatio.

In maniacal brains, when the hip lobule is high, this seems depressed, but perhaps by contrast.

Pied of the superior frontal, hence possible executive centre for goodwill, as the stem or pied of the middle frontal is the executive centre of the frontal eye. Respect. Also play, gesticulation.

The lobule sometimes suggests wings, uplifting. Fawning; probable centre of fawning in the dog.

\section{XI.-ACT OF CREATION.}

Stem, or Pied, of the Frontal Eye Lobule. The Creative Hand. The Spirit of Art.

The 'good eye and hand,' the graphic centre, writing centre, effluence, the power of artistic pro- 
duction. This lobule differs greatly in different individuals and in different professions.

Ocular expression. The good eye, the 'evil eye.'

The tendency to create works of art, to write, carve, engrave, or paint, must centre in this lobule. This lobule, stem-shaped, depicts what its bulb, body or head, the eye of imagination or ideals, clearly sees. Injury to this lobule causes agraphia or inability to write. Occasionally the lobule is double, as in the brain of Turgenieff, the novelist.

The graphicon. The technicon.

\section{XII.-Motor SpeEch.}

Broca's Pied. The Talker. Phoneticon. The Speech Centre. Exterioration of Speech.

Desire to communicate. The speaking lip, the speaking tongue, eloquence, flow of language.

This lobule, the pars basilaris of the third frontal convolution, is shaped like a knee-joint. In Gambetta, the orator, it was double.

Centre of rhapsody, recitation, oratory, talking, singing. Proclamation.

Figuratively speaking, one may say that the Muses sing in the third frontal convolution, play in the second, and dance in the first; or, reversing, that they dance in the first, play in the second, and sing in the third.

\section{XIII.-The Noble Feelings.}

Frontal Attachment. Anterior Metopic Lobule.

Lobulus capitalis, fervour of the forehead, emnoia, prothymia. The crest, the coronal. 
Good thought, good feeling, good will. Generosity. Respect, esteem, regard. Disinterestedness.

Head expression. The uplifted head.

Conjugate head and eye. Anterior superior inclination. Moral sense.

Enthusiasm, ecstasy, rapture. Agape. Himeros. Sympathy, service, devotion. Amor caritas.

Cor intellectualis. ${ }^{34}$

' Kind hearts are the gardens, Kind thoughts are the roots.'

The way to insight is through goodwill.

Love of the dead. Sentiment. Magnanimity.

The Christian graces dwell in the fore-head, the ancient graces in the back-head.

The lobule of philanthropy and humanity.

The metopon is probably the lobe of justice and equity, and of religion and morality.

XIV.-The Eye of Conception.

Head or Body of the Second Frontal Convolution.

Eye of imagination, fancy, active eye, as opposed to the receptive.

Conception, as opposed to perception. Representation is occipital, apperception is frontal.

Theories, plans, schemes, visions. Fancy, admiration and devotion. Inspiration.

The artist's vision and the poet's dream.

Idealization, love of supreme beauty. Fountain of works of the imagination. Hope. Ourania.

Admiratio. Eye of contemplation. Extasis. 
Power of idealization. Genius.

Scientific insight. Artistic insight.

This is also the centre of 'enchantment,' magic and myth, of signs, wonders, mysteries, miracles and symbols. ${ }^{35}$

$$
\text { XV.-Broca's CAP. }
$$

Lobule of language. Perhaps frontal or creative ear. Location of the verbum, the word, the created word. The logos endon, interior speech.

XVI.-The Under-Prorean Lobule. Sagacity. Control.

Union of first with other frontal gyri, beak, owl'sbeak shape in tiger and other animals; the concentration 'between the eyes,' possible seat of the intention or will. Highest concentration centre.

Concentration of the gyri of feeling, action and sight. Control, beherschung. Self-mastery.

Possibly seat of human sagacity, hence basis of substantial ideals, as in the elephant.

Suggested also as seat of intention, as opposed to attention. Concentration and direction of faculties.

Lobule of intention.

\section{XVII.-The Prora.}

Insight. Penetration. Ideas. Conception. Contemplation. Anterior Cogitation Centre.

Position directly in front. Ennoia.

Union of first and second frontal gyri.

The rectangle, the coil, the prora. 
Head of thought or of the association system of nerves. Concentration. Plato's brain.

Possible centre of control or the will.

Possible point of contemplative reason, as lateral superorbital salience is possible centre of discursive reason. Theoreticon. Nous. ${ }^{36}$ The One.

\section{XVIII.-The Orbital Region.}

Junction of eye gyrus and speech gyrus. Junction of creative eye and creative ear lobules. Frontal representation of combined eye and ear as opposed to combined eye and ear representation of posterior.

The junction of first and second frontal gyri is prominent on many cattle, notably domesticated cows. Intelligence.

Lobule of attention. Observation. Configuration.

Frontal pole. Concentration. Calculation.

Frontal pole in cattle is concentration of first, second, third, and fourth frontal gyri. Frontal base. Direction.

Opposed to frontal vertex development, perhaps practical, and opposed to ideas and imagination.

Protrusion of the lower part of the forehead common among American business men and the English man of science, hypertrophy of either the orbit, or insula.

The modern world is producing a new lower forehead and a new higher forehead.

In the lower forehead are the powers of observation, understanding and practical wisdom; in the higher forehead the powers of meditation and contemplation. ${ }^{3 \pi}$ 


\section{The Cerebral Schema.}

We may now reverse our course, and read the brain from anterior to posterior.

A, would be the prefrontal lobe, the reflectorium or conceptorium, head of reason, understanding, and will, the noeticon and logicon.

$\mathrm{B}, \mathrm{C}$, the frontal lobe, or triple frontal lobe, the communicatorium, or zone of expression. Superior gyrus is the lobe of sentiment, mimeticon; middle gyrus is the lobe of imagination and creation, graphicon; inferior the lobe of motor speech, the phoneticon.

$\mathrm{D}$ is the psychomotor, or motorium-sensory motor when acting under posterior influence; ideomotor when acting under anterior influence. It is the mental machine, the kineticon, the effectorium.

$\mathrm{E}$ is the zone of impression and highest sensation, the sensorium or affectorium, combined powers of the acousticon, the opticon, and the æsthesion.

$\mathrm{F}$ is the vital base, the appetitorium, the region of longing, the orecticon, threpticon, geneticon.

Finally, we may turn once more and regard the brain in three parts: the posterior cerebrum affective, the middle cerebrum effective, and the anterior cerebrum reflective.

\section{LOCALIZATION BY LOBULES.}

The exterior brain-surface of the brain of the carnivora - say the fox-presents to the eye an appearance of scrolls, while the exterior surface of that of ruminants and man presents that complicated 


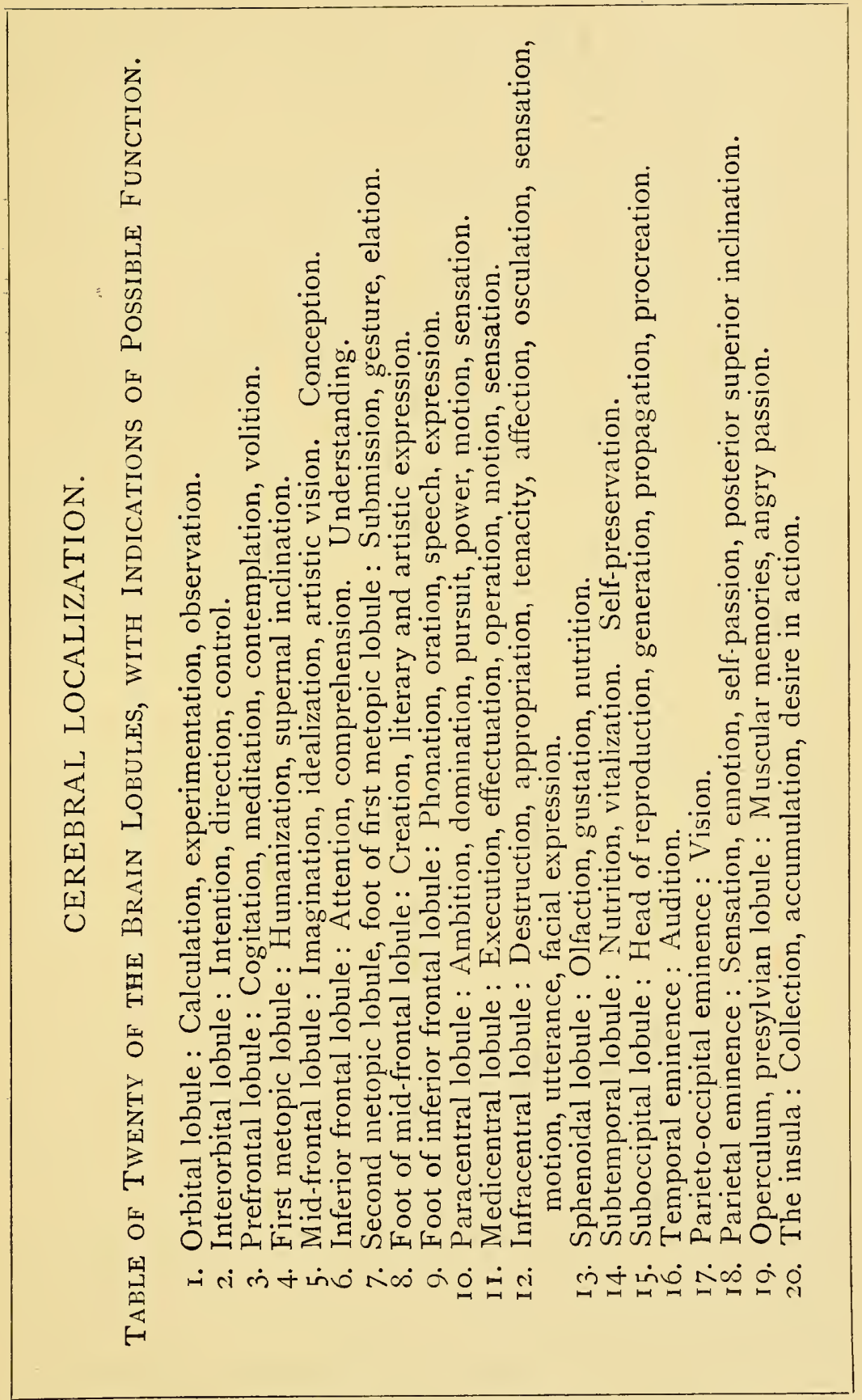


effect to which are applied the names fissures and convolutions. The inside surface of the human cerebrum, finally, conveys to us the idea of a chain of lobules.

Enumerating from anterior to posterior, and completing the entire circle, one counts no less than twelve lobules, the sub-prorean, prorean, first metopic, second metopic, paracentral, quadrate, cuneus, lingualis, fusiformis, under-temporal, sphenoidal, and hippocampal.

Finding our lobular idea by inspection of the internal surface, we may apply it to the external surface. Twenty such lobules will be found upon the external surface. These may be set down in a table (p. 97), with suggestions as to function.

\section{Psychical Localization.}

It by no means follows that each centre is a faculty. Mind is rather like a net or web, of which the centres are the knots. We know that words occupy four of these centres. Words seen are in the angular gyrus; words heard are in the acoustic area, the temporal eminence; words are spoken in the third frontal and written in the second frontal. Feelings, the sentiments, the affects, most important elements of mind, are not simple but compound. Of irascibility, one of the simplest, there are at least three centres, probably more.

From the experiments of Ferrier and the clinical observations of Magnan it would appear that we might well study the brain by theory of three, representing three orders of feeling, the parts being 
the lower, the middle or noble mind, and the higher or 'divine' mind.

Take, now, the affect irascibility. We find, by reference to Greek terms, some six species, and that these arrange themselves naturally in orders, passing from lower to higher.

Orge and Cholos, for instance, are low, almost grovelling, forms of rage. Menos and Thymos, which mean also heart, courage, spirit, reminding one of the warlike and the lionlike, these certainly are more noble and might belong to the middle region of the cerebrum, centering possibly more in the upper parietal lobules and the parts of the motor; while Zelos and Theomenia are regarded as wrath or ardour that is even saintly and godly. These ragings might rise to the higher regions, that is to the anterior cerebrum, the forehead. The manifestation of righteous indignation in the well-known sonnet of Milton may be taken as a rather doubtful example. Wounded honour ought to be a wounded parietal eminence, and the 'worm of conscience' perhaps gnaws this lobule. Conscience is the inherited reminiscence of whippings.

Thus irascibility might be a web of thought and feeling having six or seven centres of different orders, namely, the under-temporal, the superior parietal, the inferior parietal, the superior, middle, and inferior parts of the motor, and finally it might invade the soul itself, that is the high chamber of the forehead, for instance, in the impetuous rendering of good for evil. Such an act involves the transmutation of this strong and deep-seated psychic force-a conversion. 
The will also offers difficulties. The will of the slave may be located in the inferior-posterior cerebrum; the will of the master in the posteriorsuperior cerebrum; and the will of the sage in the anterior-superior cerebrum. Freedom is frontal ballast. Slavery is oversight of the posterior.

Where then, exactly, is the hegemonicon, the free soul, the highest centre of direction and control? All analogy goes to show that it must be somewhere between the eyes, hence either in the prorean or under-prorean lobules. This view, then, would give us three souls-the slave soul, the master soul, and the free soul, or the temporal type, the parietal type, and the frontal type.

Let us once more take an affect, say the grand passion, the prototype of all. The love passion is not to be located in a single centre, but in three or four. As described by Herbert Spencer it would probably occupy the entire brain, as indeed it often does.

The primary centre, the procreative attachment, eros or storge, is in the occiput. Secondary centres would be superbia, self-attachment, self-love centred in the crown; himeros and agape, divine attachment, centred in the coronal; philia, kindly and friendly attachment, the kiss of affection, or the smile of kindness, possibly in the cerebral facies or mouth lobule, the osculum. This is a question.

Human tradition and social science alike seem implicitly to recognise three orders of the feu sacrée, the lowest flame being the domestic, the next rising to the friendly and social, and the third, such as love of country, humanity, God, Nature, etc., streaming white and pure to the supernal. 


\section{Theory of Three or Four.}

Human brains are of several orders, perhaps three, perhaps four; and quality often counts more than quantity. In the lowest grade of mind the cerebrum is warmed and lit by love and light in the posterior chambers only. Such is the mental condition of the idiot.

In the next higher grade the illuminating rays throw fitful gleams into the anterior, the fore cerebrum.

In the next grade both the anterior and posterior cerebrum are fairly alive; but the posterior dominates, the mind enjoys life, but does not care for thought or sentiment.

In a still higher stage the anterior dominates. The mind is capable of idealization and control. Such is the normal man.

The highest stage is reached where the psychic force is concentrated in the direction anteriorsuperior. Here appears the genius of poets, philosophers, divines, inventors, discoverers, philanthropists.

Cerebrums of this order may be active-that is, creative; or they may be passive-that is, appreciative.

'The rarest thing in the world is spirituality'; the rarest thing is the full flushing of the anterior brainchambers with light and love and spirit and will.

\section{Brain Contents.}

Bearing in mind the theory of three, we may name the posterior, mid, and fore cerebrum respectivelysensorium, motorium, and reflectorium, or the receiver, 
the motor, and the reflector; or we may call them the brain of passion, brain of action, brain of reflection; or we may call them front, middle, and posterior. Representation also is posterior.

Youth is impassioned; it is posterior. Manhood is militant; it is central, or posterior-superior. Maturity is thoughtful; it is anterior, or anteriorsuperior. The brain is a mansion; the posterior chambers of the cerebrum are filled with sensations, emotions, passions, and such elements as perceptions, memories, reminiscences. Those of the mid cerebrum are filled with efforts, operations, energies. The high chambers of the fore cerebrum are filled with ideals, fancies, and sentiments, and with notions, conceptions, ideas, theories, judgments, comparisons, reasons.

\section{The Psychometric Schema.}

The segmenter, cerebral schema, or psychometric scale, as I have used it in the study of psychology during the past six years, consists of a hemicycle-a paper hemisphere-divided into segments.

It may be divided by two, folded in three, or in four, five, six, seven, or more parts.

If the seven theory is used, the central space is the motor, and anterior to it are the segments of the first, second, and third forehead-say, the segments of attention, conception, expression; and behind it the three of the post-head-say, the segments of sensibility, perception, and impulse. These divisions are less arbitrary than they may at first appear. 


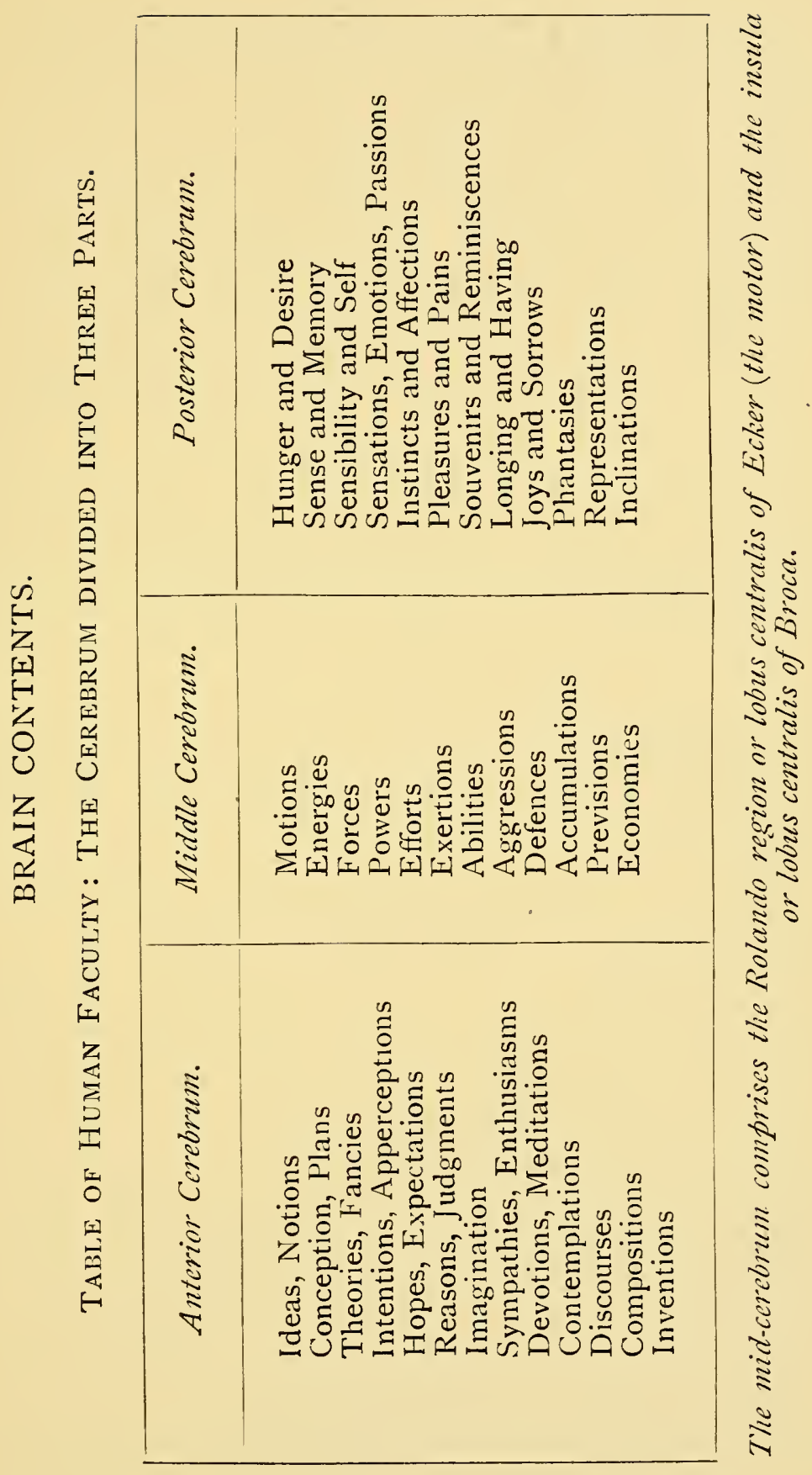


The segmenter, or fan, open to a scale of seven, may be drawn as follows :

SUPERIOR.

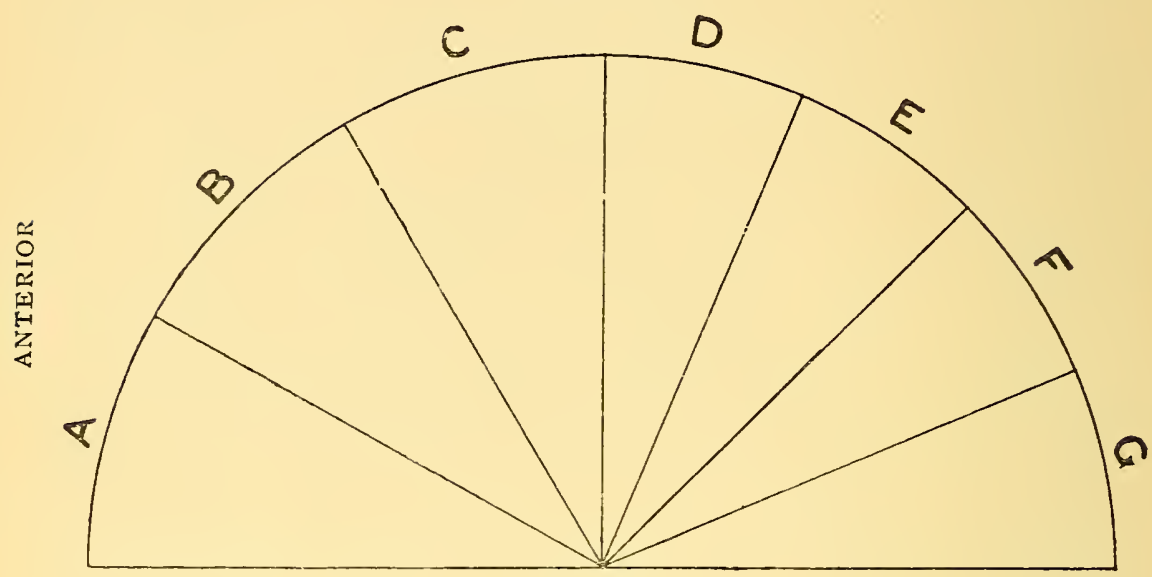

INFERIOR.

These 'parts of the soul' may be provisionally designated by Greek terms, most of them already well known.

$\mathrm{G}$ the desiring or longing soul-threpticon, auxeticon, geneticon.

$\mathrm{F}$ the perceptive and mnemonic soul-acousticon and opticon.

$\mathrm{E}$ the sensitive and personal soul-algedonicon or asthesion, or patheticon.

$\mathrm{D}$ the energetic and effective soul-the energeticon or kineticon.

C the expressional soul-mimeticon, poeticon, phoneticon.

$B$ the sentimental and imaginative soul-head of the mimeticon, poeticon, and phoneticon.

A the reasoning, judging, deciding, directing, and self-controlling or free soul-noticon, logicon, bouleticon. 
The posterior four of these segments, G, F, E, D -namely, the impulsive, perceptive, sensitive, active parts of the soul-will be found grandly rounded in the ox and the lion, where, indeed, they appear to constitute substantially the whole soul. The grandeur of the ox-brain appears in the impulsive or temporal segment, and that of the lion in the motor or parietal segment.

The segmenter may be used as follows:

\section{THEORY OF TWO.}

We fold the segmenter into two folds. The scheme thus represents the soul in two parts, the logon and the alogon, or the higher soul and the lower soul.

THEORY OF THREE.

We fold the segmenter into three folds. The scheme now represents the affective soul, the effective soul, and the reflective soul.

THEORY OF FOUR.

We fold the hemisphere into four folds. This gives us four 'parts of the soul' thus: the soul of passion and the soul of action, the soul of sentiment and the soul of reflection.

\section{THEORY OF FIVE.}

Regarding the cerebrum in five parts, we call them the soul of impression and the soul of expression, the soul of impulse, the soul of action, the soul of reflection.

\section{THEORY OF SIX.}

Folding the segmenter into six plaits would give us divisions which, naming in order from front back- 
wards, would then be : first division thought, second division word, third division deed, fourth division feeling, fifth division sense, sixth division (temporal) appetite.

\section{Theory of Seven.}

Dividing the sphere by folding the meter into seven parts, we may locate as follows:

Will and reason in the first fold (frontal).

Imagination and fancy in the second fold (frontal).

Impressiveness and desire to communicate in the third fold (frontal).

Energy and ability in the fourth fold (parietal).

Self-consciousness in the fifth fold (parietal).

Thirst for knowledge in the sixth fold.

Life and new life in the seventh fold (temporal).

\section{Theory of Eight. Eight 'Parts of the Soul.'}

The meter may be made in the simplest way by taking a sheet of notepaper and plaiting it into eight equal folds.

By the theory of eight we now divide the soul into the following parts, naming the functions of each in Greek.

The posterior folds are: Orexis, Aisthesis, Pathesis, Kinesis.

These would fill the posterior, or the temporal and parietal cerebrum.

The anterior folds, naming from the front backwards, are: Boulesis, Noesis, Hypolepsis or Epinoesis, and Poesis. 
These would fill the frontal cerebrum.

Reading the entire eight from posterior to anterior -orexis, aisthesis, pathesis, kinesis, poesis, epinoesis, noesis, boulesis-would be to name the parts of the soul thus: the desiring soul, the perceptive or representative soul, the sensitive soul, the active

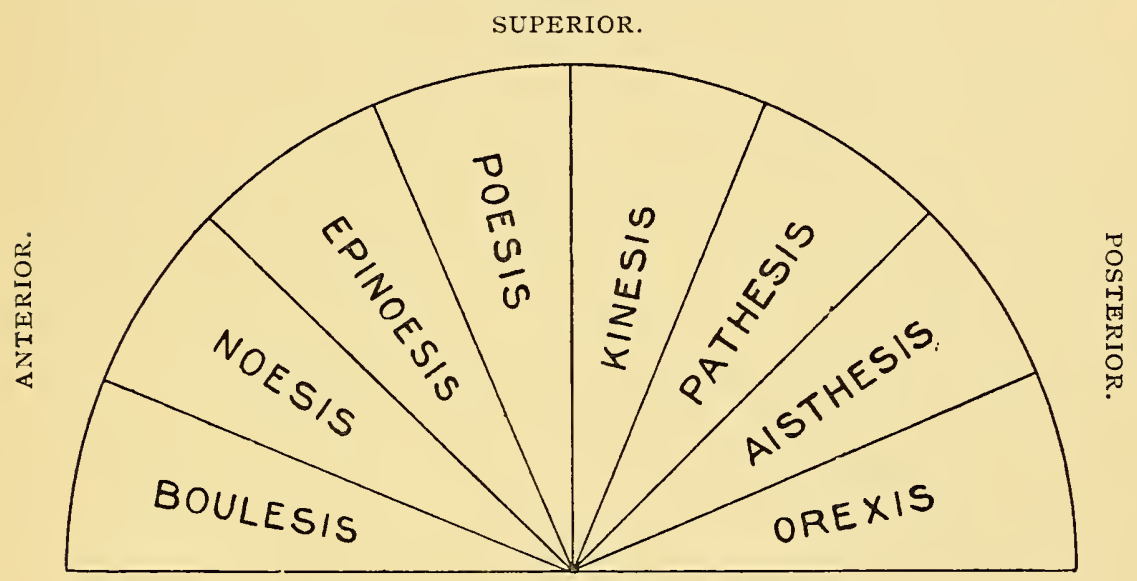

Cerebral Theory of Eight.-Eight 'Parts of the Soul.'

soul, the expressive soul, the imaginative soul, the contemplative soul.

Mind is a force. It might be claimed that, when all is said, the best name for the brain is the psychodynamo. It is a spiritual coil, a luminous globular form, a globe of wondrous concentration and of awful power. To nearly every one of the eighteen lobules given in the first cerebral diagram we may with propriety apply this word.

Parts I., II., III. are lobules of nutritive power, vital power, generative power.

Parts IV., V., VI. are lobules of ear power, eye power, and selt power. 
Parts VII., VIII., IX. are lobules of dominant power, executive power, and tenacious power.

Parts X., XI., XII., XIII., XIV., XV. are the powers of sentiment, the power of art, and the power of language.

Parts XVI., XVII., XVIII. are the power of will, the power of thought, the power of science.

Such is the coil of human force, such is the psycho-dynamo.

On the other hand, it might be held, in view of the predominance of the eye, the ear, the sense, and reason and speech, that power is not the true word, but rather that the word should be faculty, for dynamis may be either a power or a faculty.

Such things as ' hunger, und liebe,' however, appear to be typically neither powers nor faculties. Can the dynamis also be an impulse?

The question is settled by comparative cerebreology. It must be remembered we are not dealing with one order of brain, but three-the herbivorous, the carnivorous, and the omnivorous-say, the type taurus, the type leo, and the type homo.

To the soul of taurus the Maker has given hunger, life, and love. This is the temporal order of brain.

To the soul of leo $\mathrm{He}$ has given pride, vigilance, vehemence, and grasp. This is the parietal order of brain.

To the primate $\mathrm{He}$ has given light, mildness, and dexterity; and to the magnate, with these as a foundation, He has added the lobules of the agape and the nous, the eidos and the logos. This is the frontal order. 


\section{NOTES AND REFERENCES}


Cæsar's hand and Plato's brain, Lord Christ's heart and Shakespeare's strain.

Emerson. 


\section{NOTES AND REFERENCES}

I.

The Human Plane.

The three professions see men as they are, that is, desiring to be sound in mind, body, and estate. They see men as higher than animals and lower than gods.

2.

\section{The Balance.}

As men who have kept their balance we may cite Goethe, and Taine, and Matthew Arnold.

$3 \cdot$

Cranium, Brain, and Soul.

The beautiful work of Huschke, "Schädel Hirn und Seele,' written nearly a hundred years ago, is still worth looking over.

$4 \cdot$

The Cerebral Sphere.

The luminous cerebral sphere is a being and the highest, en-telos-echein, the only perfect, perfectihabia. For the idea of the luminous sphere see Erdman's 'History of Philosophy.' 
5 .

The Brain resembles the Creature.

As the walnut is in appearance a crumpled tree, so the brain appears to suggest the crumpled eidolon-man in a nutshell.

6.

The Aggressive Jaw.

The Charles V. jaw is not necessarily 'bad,' but aggressive. Charles V. and Philip II. have the hostile jaw; Cæsar and Abraham Lincoln the contrary. One says, 'I must kill' ; the other says, 'I must die.'

\section{$7 \cdot$}

Brain of the Panther.

The fore cerebrum of the panther, fiercest of quadrupeds, shows a lobe of four sickle-shaped gyri, reminding one of the curves of the feet of a dragon-fly, the fiercest of all insects. The psychomotor lobe in all the carnivora presents this aspect.

8.

Cerebral Scroll-work.

The brain is beautiful. A cast in gypsum or alabaster of the brain of a fox or gazelle is far more beautiful than any sea-shell or the body of any bird or insect, at least, when measured by a classical canon-that is, any canon other than the romantic, the Oriental, the rustic, or picturesque. A person who likes Athens or Greek vases will like the cerebrum of a gazelle. 
9.

The Prorean Lobule.

For a painstaking anatomy of the dog's brain see Langley.

IO.

\section{Greer Vases.}

Greek ceramic, Greek plastic, is in both form and decoration the acme of art. In scrutinizing the brain, one is constantly reminded of Hellenic rhythm, symmetry, and symbolism. The brain is like Hellenic technique.

\section{I.}

Eidolon of a Trotting Horse.

This observation is based upon two brain-mummies which I prepared by the dry process (aqua fortis, bichromate, carbolic, glycerine, oil of cloves): one that of an old working horse, the other that of a thoroughbred mare, a valuable animal that succumbed to the colic. It is thus by the comparison of two that we may find the shell or mould of the eidolon (en-telos-echein) - the entelechia. For this reason the student should have two brains in hand at once. His theses then are truths. For instance, the prow of the wolf-brain is long; that of the tiger-brain is short, etc. No method of study is better than comparison.

I2.

The Spirit of Vision creates the Corporeal Eye and the Cerebral Eye.

Do the cerebral eye and the cerebral arm become deformed by special occupations? I am publishing 
photographs of these brains in various medical journals. If the appearances noted should prove to be only accidents and coincidences, no one will be more willing to accept such proof than myself.

I3.

The Profession impresses the Cortex.

Those interested are referred to the plate of the speech lobule of the orator Gambetta in Poirier's 'Anatomy,' and to the photographs of the cerebrums of the noted astronomer published by Retzius.

Man is a Sensible, Active, and Intelligent Being.

Nutritive sense, vital sense, generative sense, ear sense, eye sense, muscle sense, cutaneous sense, common sense, good sense, belong to the posterior cerebrum.

Foot sense, hand sense, and facial sense, with foot motion, hand motion, and mouth motion belong to the medi-cerebrum.

Head intelligence belongs to the superior frontal lobe, eye intelligence to the middle frontal lobe, ear and mouth intelligence to the inferior frontal lobe. These compose the anterior cerebrum.

In figure 2 it will be seen how naturally the cerebral sphere divides into three parts-a middle, an anterior, and a posterior.

The human brain after death is an autobiographical manuscript. The brain after death is an autobiographical sculptured scroll. It is more valuable than any manuscript; it is more beautiful than any sculptured scroll. 
I5.

The Contrat Social.

A contrat social between man and the animals is hardly more absurd than that of Rousseau. Epochs are not made, but grow ; nevertheless, the Pastoral Age will always remain in the mind of man as most fortunate, most golden.

\section{I6.}

\section{Cerebral Anterior and Posterior.}

From study of the cerebrum of ruminants new born one seems to see that the posterior half represents the body and the anterior half the neck, with its head and shoulders. The mesial surface of the cerebrum of a fœtal zebu (Bos indicus) reminds one of the form (morphe) of the body of a kangaroo. The mesial surface of the cerebrum of this brain contrasts with the mesial surface of that of man, much as the vertebral figure of the kangaroo contrasts with the vertebral figure of man.

\section{I7.}

Frontal Attachment.

The feelings of ideal attachment in the dog and sheep are cerebral anterior, as those of real attachment are cerebral posterior. Anterior feelings are to be located both in the mouth zone and the head zone. The kissing or licking centre is infra-central; the adoring or fawning centre, it would appear, is precentral, or anterior superior. 
I 8.

The Sensus Fixus.

The senses may be grouped in various ways, each suggestive.

The Theory of Five.-The five organs of sense in man are the eye, the ear, the nose, the tongue, and the hand. Other senses lead up to the typical five.

The First Theory of Six.-Two capsular senses, sight and hearing; two groove senses, smell and taste; two corpuscle senses, tact and the genesic sense.

The Second Theory of Six.--Sight and hearing, taste and smell, muscle sense and touch.

Theory of Two.--Summit senses and sloping senses. Eye and ear are located highest on the sphere ; these are summit senses.

Second Theory of Two.-Eye is a culmination of external or conical sense ; ear is a culmination of internal or undulatory sense.

Theory of Three. - Sight, hearing, and touch. Taste is nutritive, or chemical touch ; smell is 'touching at a distance'; muscle sense is deep active touch; the pudic sense is a shrinking from touch.

The Theory of Eight.-Named from both organs and nerves. I. Nostril sense, or olfactory sense. 2. Tongue and palate sense, or glosso-pharyngeal sense. 3. Visceral sense, or pneumo-cardo-gastric sense. 4. The tender sense, or sympatheto-splanchno-pudic sense. 5. Ear sense, or acoustic sense. 6. Eye sense, or optical sense. 7. Muscle sense, or muscular nerve sense. 8. Cutaneous sense, or cutaneous nerve sense.

The aim of the encephalographer is to find and demonstrate the cerebral heads of these eight sets of nerves.

This being done, the psychology of Ovis or Felis could be worked upon some such lines as the following: 
Muscular Sense and Sensations, Muscular Memories and Emotions, Muscular Ideas and Passions-and so for the remaining seven. One could go through the eight first by synthesis, making a biography, and next by analysis, making a characterology. Interesting biographies of animals are written by Ernest Thompson.

The Theory of Four.-From the study of the brains of cattle, sheep, and Sus scrofa, it appears to me there are four senses: (I) Internal touch; (2) external touch; (3) hearing, the high spirit of internal touch; (4) sight, the high spirit of external touch.

I9.

Social Principle. The Synagogue Instinct.

Agir and pativ. Animals are capable of action and feeling, hence they have souls. In sheep, bees, and men the soul rises to a high pinnacle, the social principle the conception of a collective ideal head. The collective head of the bees is the matriarch; with sheep it is the patriarch; with human beings it is patriarch, matriarch, king, queen, god or goddess, or finally, a mere word or phrase, an idea, 'notve idee.'

The qualities which gradually build up the metopon in the primitive man are submission and eagerness (prothymia). These two social virtues may be well studied in that strangely humanized animal Canis familiaris. His 'idée' is the master.

The idée of the master himself, 'notve idée,' is either 'Liberté, Egalité, Fraternité,' or ' le Vrai, le Beau, et le Bien,' or some other. Duty. God.

The social principle shines forth clearly in one of the noblest books by one of the noblest men, the 'Meditations' of Marcus Aurelius.

Sheep, bees, and men have the instinct of society - the synagogon, or 'social principle, the coinonicon pathos. 
20.

\section{Attention and Intention.}

The pre-frontal lobe must be the point of most advanced intensity of will and idea-die wille und die vorstellung. It appears to me, from the study of the brains of ruminants, that die wille must concentrate in the medial portion of this lobe, and die vorstellung in the lateral portion. The scientific proof is conclusive that visual and vocal faculties are lateral; affectivity and force, then, must be medial.

\section{$2 \mathrm{I}$.}

Boulé, Boulesis.

While the language of the cerebral base is 'I want' -for instance, like the cry of an animal of the ox kindthe language of the cerebral arch is 'I will.' It is like the resolute action of the animal that mankind has most respected-the bull. There can be no question as to etymology; bo, bous, bull, boulé, vole, and volition are one.

Boule means resolution, and the Bos taurus male is simply the most resolute animal on the globe. This quality makes him more than a match for the lion.

Along the marginal arch we must look for three centres: force, goodwill, and resolution. These locations may be paracentral, frontal, and pre-frontal. In Canis the centre for the tail is pre-frontal; it is between the eyes. It is an interesting question whether with the dog, the bull, and the lion the tail is the index of the will.

\section{2.}

\section{Cerebral Dorsum and Ventrum.}

The arch of the brain must give tone to the overcorps or vertebral half of the body, and the base of the brain must give tone to the undercorps or visceral half. 
The eye appears to be the flower of the over-outer, and the ear appears to be the flower of the inner-under. Life culminates in the eye and ear.

\section{3.}

\section{EfFEctive Wrath.}

The vials of wrath-that is, the feelings proper to feline jaws and claws-may be in these lobules, or may be in the lobules just posterior. The latter view is highly probable. Wrath is passion, effectiveness is action. The treasury of wrath may be therefore the pre-sylvian lobule.

The lamb is agathos, man is agathos, kalos, alethes, or celestiality, ideality, and 'humanity.' The lion, judged by his brain, is man's antithesis.

\section{4 .}

Anterior and Posterior Dignity.

The lion has primeval, native, or posterior nobility, generosity, magnanimity; man has the supernal, reflected, or anterior nobility, generosity, magnanimity. One is a post-central lobe, the other a pre-central lobe. The leonine species of dignity is parietal, the human or gottliche species is frontal. The later Roman Emperors possessed the former, but crowned the latter. See their portraits.

How shall we describe the great soul, the animus magmis?

It is one sufficiently long to see the world whole, and to keep it ever in view; it is one sufficiently high to feel that it possesses the world; it is one sufficiently broad to carry the world all night upon the shoulders, and to set it down in the morning and create an impression upon it; 
it is one sufficiently deep to sustain the burden, and to keep up the tension required.

Such souls were Scipio, Cæsar, Augustus, Hadrian. Such souls were Plato, Aristotle, Lucretius, Cicero.

How shall we describe the great soul, the intrepid, the generous?

It is one that sees the world, loves the world, lives for the world, and dies for the world. This is one species of the megalopsychos.

\section{5 .}

Sphenoidal Lobe, Head of Nutrition.

One may perhaps add the sphenoidal, as lobe of nutrition or hunger. We must avoid the 'errors of Gall.' In the future history of science his name will probably stand higher than at present; nevertheless, a large proportion of the localizations of phrenology are fictions, and the remainder not properly grounded. The ways of the phrenologist are too much those of the charlatan. The practitioner does not work miracles; the physician asks the patient his symptoms; the lawyer requires the client to state his case ; the minister looks for a confession.

Students must avoid the terminology of Gall and Spurzheim, as it will create obstructive association. The science of the exterior is cephalometry, not organology. It must work with reference to general types. 'Bumps of the head and lines of the hand' make sciences proper for farmers' almanacs. This is the view at present.

For eucephalics, or the study and appreciation of the head, the perfect or noble part, one must take, first, the works of Pheidias and his contemporaries; next, the Greek and Roman busts; and, thirdly, the works of Michael Angelo and Raphael. Other artists are of little account in comparison. 
Pheidias, Michael Angelo, and Raphael have seen that the head is of importance. For most other artists anything will do for a head. Correggio preferred the posterior extremities; Velasquez preferred the soles of the feet. Rembrandt delineated faces, Rubens bodies; neither of them delineated heads.

\section{6.}

Cerebral Hemispheres.

The brain is of the greatest interest to artists. The fissures and convolutions may be quickly learned from any good anatomy. As the simplest preparation for the study of cerebral psychology one may without great expenditure of time look at the brain in some anatomy, and at the work of Ferrier, or that of C. K. Mills, or that of Dana. One must know the fissures, the gyri, and the physiological centres.

\section{7.}

The Frontal Dome.

The frontal is the transcendent sphere; the dome of the Alethes, the Kalos, the Agathos-that is, of the true, the beautiful, and the good, or of celesticity, ideality, and humanity. It is the shining lobe, the shell of the brilliant spirit. Light radiates to every part.

The prefrontal, as part of the frontal, is the dome of the Alethes, which, by theory of two, is theoretical truth and practical truth, or by theory of three is pure reason, good judgment, and free will.

\section{8.}

The Paracentral Lobule.

In states of mental exaltation this lobule is elevated or swollen; in states of mental depression the lobule is 
relaxed or elongate. This needs confirmation. I base it upon some ten cases of mania and two cases of melancholia. The evidence is insufficient; one requires fifty cases of each to draw a true conclusion. The two best laws of observation for the student are these: "Multiply instances for induction,' 'Aberrant cases yield crucial tests.' These rules are found in Mill's logic. The great organon, however, is comparison. Comparison by contrast establishes analogies; comparison by series establishes homologies. By constantly seeking the ideal or the best, we arrive at archetypes and exemplars and the perfect, the telos.

The Stoma.

This lobe ought to be the head of the olfactory glossopharyngeal and pneumogastric nerves. Impressions do not follow gyri nor fissures, nor even lobules. The spirit seems perpetually striving to create a peculiar form, a shade of its own, an eidolon, a shadow of itself. We must endeavour to discern these eidola.

$$
30 .
$$

Temporal Underlobe.

The evidence for this lobe is slender and conflicting. Ferrier finds the lobule sensory; C. K. Mills appears to regard it as auditory. My own views were published last year in an article in the Philadelphia Medical Joumal, entitled, 'The Struggle for Life Lobule.'

\section{I.}

Occipital Underlobe.

I have described this lobe as found in 50 cattle, I 5 sheep, 6 lions, I panther, and 300 human beinss, in a series of articles in the New York Medical Journal. 
The 'new method in brain study' rests upon comparison of the gyri by means of paint. I prepare the brains of two herbivores, two carnivores, and two primates, by the dry process; I then make in gypsum or alabastrine six casts of each. Upon the first set of the series I paint homologous gyri; upon the second set homologous lobules; upon the third set the physiological centres; upon the fourth set the lobes; and upon the fifth various sections, or the hemispheres. The sixth set remains plain. I take six or eight photographs of each brain, and reproduce important lobules in wax.

\section{2.}

Parietal Eminence.

The vast tract uniting mesial and cranial surfaces is well shown on the diagrams of C. K. Mills, who regards the whole region as sensory. Just as aisthesis and kinesis, or sensibility and activity, are opposed, so this tract appears to erect itself in opposition to the Rolando tract or motorium of Ferrier. Take an example. No doubt in a duel the C. K. Mills lobe feels the insult, and the Ferrier lobe wipes it out in blood. There is a pride lobe and a power lobe.

The self rises upon the remembrance of pleasures and pains that is upon the eminence of hurtings and caressings. Jouffroy in his 'Mélanges' rightly says that 'l'amour du soi' is 'la loi suprême de la sensibilité.' According to some thinkers, pleasure and pain are the same thing, viz., excitation, feeling; or the quick. Love is pain-pleasure; labour is pleasure-pain.

A truer science of Algedonics-that is, of hurtings and caressings-is needed.

Feelings are either joys, summer feelings, furtherances and dilations of the soul, or they are tonics, winter feel- 
ings, contractions of the body and furtherances of the soul, or they are passive pains, sufferings, psychalgia, neuralgia, etc., which indicate weakness or lesions of the body, and may be to the soul either furtherance or hindrance, or, finally, active pains, voluntary agonism, 'painstaking,' which is liberal furtherance of both body and soul. 'For the artist there is no such thing as pain or pleasure, only states of excitement that lead to production.'

The important law is that pains are exceeded in amount by pleasure--in other words, the greatest truth is that life and happiness ave synonymons terms. "Life to me is a rapture!' cries the living soul.

33 .

Superior, Middle and Inferior Motor.

Possibly the constructive instinct, or, rather, the instinct of doing, is in the middle motor, the destructive instinct in the inferior motor, and the instinct of accumulation and possession in the under motor or insula, the large lobe hidden under the lips of the inferior motor. The passion of anger may be in the lobule just posterior, the presylvian.

\section{4 .}

\section{Amor Intellectualis.}

Of the amour noble, Ad. Franck writes as follows:

' Rien de commun entre ce brutal penchant, ce mouvement aveugle de la nature animale et le noble entraînement que excite dans une âme intelligente et libre tout ce que est beau, tout ce qui est bon, tous qui intéresse par le souffrance ou par la grace.'

He repeats the statement that common love is blind, and that noble love is wide-open-eyed. The whole article 
'Amour' in the 'Dictionnaire des Sciences Philosophique' is worth reading.

It appears proved that amour commun crowds the eyes, shuts the two lids together, causing the eyes to squint. We find this in Tolstoi's 'Resurrection' and in the Latin classics. Amour noble, on the contrary, pulls the lids apart, rolls the ball of the eye, and turns the head upward. To say, however, that the two affections have rien de commun is equivalent to saying that the head and the body have nothing in common, or that amour dans le maison and amour dans l'église have nothing in common; or, again, that love of the living and love of the dead are not the same, which is perhaps true in one sense.

Of the amour noble, Ad. Franck recognises four grades:

I. The lowest, love of all living things.

2. Love of our fellows and of ourselves considered as moral beings and divinely imaged.

3. Love of the ideal and of intelligible realities, the good, the beautiful, the true-'dans leur essence le plus pur.'

4. Love of Dien, the perfect unity of these principles, the plenitude of these three principles.

What is the love force? It is held that it is a tender attraction. Man is drawn by the heart-strings to all lovely things. Thus it is in the living world the equivalent of gravitation, cohesion, adhesion, affinity in the non-living world. This idea, however, appears inadequate. The love force is rather a never-dying flame; it is perennial or immortal life, the igneform aeriform pneuma. Life is persistent; it cannot be destroyed.

Amor familias, or the common affect, is posterior inferior; amor caritas, or the noble affect, is anterior superior, yet they seem to be not two, but one. Family affection is both sensuous and ethical. As the members of a family die one by one, the flame in the brain of the survivors rises into the anterior superior chambers. 
In love of the dead the stages or successive links appear to be attraction, attachment, tenderness, melting, effusion, union. It is a singular truth that we must all unite ourselves to the dead.

Two writers only, according to Ad. Franck, have treated the subject of amor worthily-Plato in the 'Symposium,' and Leone Hebreo in the 'Dialoghi di Amore.' In poetry we may add Dante and Michael Angelo, and in philosophy possibly Giordano Bruno and Jonathan Edwards. The highest law is 'love of being.'

The first and second, or superior and middle frontal, gyri constitute the 'conjugate centre of head and eyes,' the lobus supremus.

' La vrai bien descendant de la source première, La justice sereine et la pur lumière.'

This centre, then, is the Kalokagathos, the man beautiful and good, the man in the image of the god.

The nous is the Divine light in the soul.

The pneuma is the Divine fire in the soul.

35 .

The Frontal Tri-lobe.

Looking at the frontal brain from the side, it would appear from the data we have that the superior frontal is the moral gyrus, the mid-frontal is the poetical gyrus, and the inferior frontal is the logistical gyrus.

Four of the best books for moral practice are: Aristotle's 'Ethics,' Cicero's 'Offices,' Marcus Aurelius' and Spinoza's 'Ethics.' The student is recommended to choose two or three of these, and keep them at hand. Every cerebrologist is necessarily a moral teacher. 


\section{6.}

The Prefrontal Lobe.

The three lobes, XVI., XVII., and XVIII., constituting the forehead of man as seen from the front, make the abstractorum, or forehead of thought. On human brains prepared by the Charcot process, the prefrontal lobe sometimes stands a little apart from the rest of the brain, that is, it presents a slightly different appearance, differentiating it from the frontal. This small space is the acme of the world, as far as man is concerned. Here is the 'Higher Psychical,' here the will and the reason.

It is necessary for us to locate carefully in the forehead of man the two or three or four supreme lobules. Two forces rule the universe, heart force and head force; otherwise, fire and form; otherwise, the pneuma and the eidos. In the brain of man we may call these enthusiasm and intellect. The supreme enthusiasm, then, is metopic; the supreme intellect is prefrontal. Chartres and Amiens were built by the supreme enthusiasm; Athens was built by the supreme intellect.

Enthusiasm and Sentiment, Religion, Literature, Art, Music, the sentimental head, is frontal; Philosophy and Science, the abstract head, is prefrontal. There is reason to believe that the theoretic dynamis, the speculative intelligence-de intellectu vero contemplatio-comes to a head divectly in front. The concentrating point may be more lateral, or may be more medial.

Perhaps the best introduction to psychology is through P. Janet, Jouffroy, Ribot, and Wundt. Wundt is a founder. In the end, of course, all must turn to the two pure well-springs, Plato and Aristotle. There is only one sculpture in the world, and only one psychologythe Hellenic. Other peoples know how to extend; the Greeks knew how to concentrate. 


\section{Five Classes of Souls.}

According to cerebrology, souls may be classed or defined as follows:

Useful souls are much alive in the temporal chambers, such are agriculturists, mechanics, merchants.

Strong souls are much alive in the parietal regions: kings and queens, commanders, statesmen.

Good souls are much alive in the metopic chambers: divines, philanthropists and sisters of charity and the saints are examples.

Beautiful souls are much alive in the summit chambers, or those of the sides of the forehead : artists, poets, and scholars live here.

Truthful souls are much alive in the prefrontal chambers, those of the prosopon or bare forehead: such are philosophers, men of science, and, we may add, the mothers of philosophers and men of science.

Nevertheless, human nature is no system of castes. Men are born free and equal, for each has possession of all powers and faculties. Each soul is the whole sphere of the whole humanity. Each has the five 'stately mansions'; he may occupy them according to his goodwill and pleasure. He may elect to be a useful soul, a strong soul, a good soul, a beautiful soul, a truthful soul. To occupy all the chambers is to be well balanced and fitted to live. To strive progressively toward the high chambers 'as the swift seasons roll' is to be heroic; to live much in the high chambers is to be noble.

THE END.

B.sillière, Findall and Cox, Henrietta Street, Sirand. 

